the

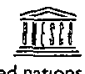

united nations
cational, scientufic

and cultural

abdus salam

international

centre

4

international atomic for theoretical

physics

IC/2003/80

SEISMIC MICROZONING FROM SYNTHETIC

GROUND MOTION PARAMETERS:

CASE STUDY, SANTIAGO DE CUBA

Leonardo Alvarez

Franco Vaccari

Giuliano F. Panza

and

Ramón Pico
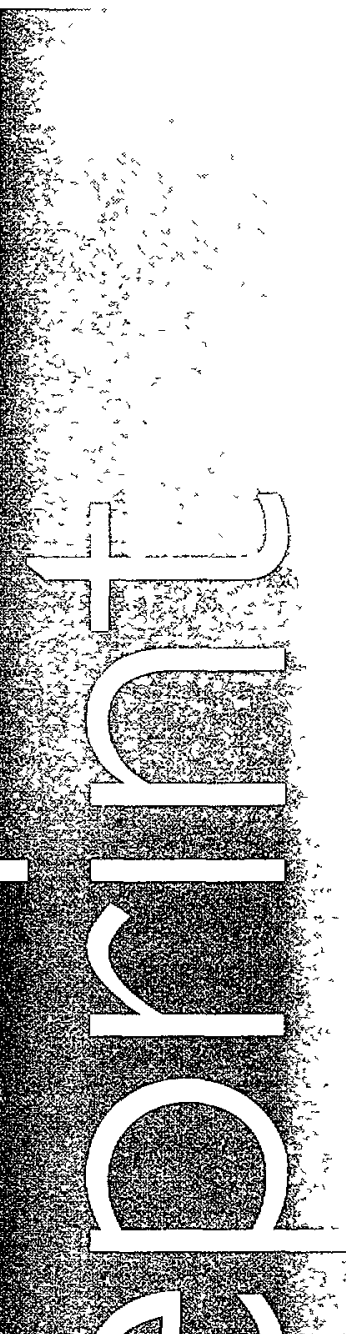
IC/2003/80

United Nations Educational Scientific and Cultural Organization and

International Atomic Energy Agency

THE ABDUS SALAM INTERNATIONAL CENTRE FOR THEORETICAL PHYSICS

\title{
SEISMIC MICROZONING FROM SYNTHETIC GROUND MOTION PARAMETERS: CASE STUDY, SANTIAGO DE CUBA
}

\author{
Leonardo Alvarez ${ }^{1}$ \\ Centro Nacional de Investigaciones Sismológicas (CENAIS), \\ 212 No. 2906, La Coronela, C. Habana, CP 11600, Cuba \\ and
}

The Abdus Salam International Centre for Theoretical Physics, Trieste, Italy,

Franco Vaccari, Giuliano F. Panza

Dipartimento di Scienze della Terra, Università di Trieste, Trieste, Italy

and

The Abdus Salam International Centre for Theoretical Physics, Trieste, Italy

and

Ramón Pico

Instituto de Cibernética, Matemática y Física (ICIMAF),

E No. 309, el 13 y 15, Vedado, C.Habana, CP 10400, Cuba.

MIRAMARE - TRIESTE

August 2003

\footnotetext{
${ }^{1}$ Corresponding author. E-mail: leoalvar@ictp.trieste.it
} 


\begin{abstract}
Synthetic seismograms (P - SV and SH waves) have been calculated along 6 profiles in Santiago de Cuba basin, with a cutoff frequency of $5 \mathrm{~Hz}$, by using the hybrid approach (modal summation for a regional (1D) structure plus finite differences for a local (2D) structure embedded in the first). They correspond to a scenario earthquake of $\mathrm{M}_{\mathrm{S}}=7$ that may occur in Oriente fault zone, directly south of the city. As initial data for a seismic microzoning, the characterisation of earthquake effects has been made considering several relative (2D/1D) quantities (PGDR, PGVR, PGAR, DGAR, $I_{A} R$, etc.) and functions representative of the ground motion behaviour in soil (2D) with respect to bedrock (1D). The functions are the response spectra ratio $\operatorname{RSR}(f)$, already routinely used in this kind of work, and the elastic energy input ratio $E_{l} R(f)$, defined, for the first time, in this paper. These data, sampled at 105 sites within all the profiles have been classified in two steps, using logical combinatory algorithms: connected sets and compact sets. In the first step, from the original ground motion parameters or functions extracted from the synthetic seismograms, 9 sets have been classified and the partial results show the spatial distribution of the soil behaviour as function of the component of motion. In the second step, the results of the classification of the 9 sets have been used as input for a further classification that shows a spatial distribution of sites with a quasihomogeneous integral ground motion behaviour. By adding the available geological surface data, a microzoning scheme of Santiago de Cuba basin has been obtained.
\end{abstract}




\section{Introduction}

Seismic microzoning was introduced in seismological practice more than 40 years ago. The use of microtremors for estimating some characteristics of foundation soils dates from the fifties [1]. The classical book of Medvedev [2] summarises the results of Soviet scientist's initial experiences in that discipline. They used as parameter for microzoning the value $\Delta \mathrm{I}$, defined as the increment (or decrement) of the expected macroseismic intensity over the one corresponding to a "reference soil", in which it is expected to occur the macroseismic intensity predicted by regional seismic hazard assessment ("base degree"). The data used for that purpose are, first of all, of engineeringgeological character, complemented with microseisms' and/or microearthquakes' measurements. The further development of the Soviet school of seismic microzoning, due to the fact that building codes were prepared always in terms of macroseismic intensity, was directed to the upgrading of the methods to calculate the $\Delta I$, the basis of a microzoning map, complemented with the analysis of the spectral behaviour of soils through transfer functions calculated by different methods [3, 4]. In western countries, this kind of work began later, and followed a different path. Seismic hazard was mainly estimated in terms of peak acceleration values, and microzoning was directed to the estimation of relative amplification (a transfer function) of expected ground motion with respect to a point (believed to represent the bedrock), the "reference site" $[5,6,7]$.

Another variant, widespread in present times, was the spectral ratio method [8], that considers the Earth as a simple two-layer model (sediments over bedrock) and assumes that the ratio of horizontal to vertical component of microseisms can be related to the transfer function of $S$ waves. Although the use of this method is very popular, there are serious objections to its validity [9].

The key point in the microzoning studies is to determine what is a "reference soil" for $\Delta \mathrm{I}$ calculation, or a "reference site" for transfer function evaluation, which is not a simple process. In the case of the "reference soil" the procedure can be divided in two parts: a) to identify a kind of soil, present in the area of study, that is consistent with the regional hazard estimation, b) in the area covered by this kind of soil, to select a point or a group of points, considered "characteristics" of this soil, which can be used as reference for some relative calculations of microseisms' or microearthquakes' measurements, of acoustic impedance, etc. In the case of the "reference site" the problem is to find a site that can be considered as bedrock, to be used for the definition of the transfer functions of the sedimentary cover.

Modelling is a way to avoid this problem. If the regional structure is known, it is possible to obtain realistic synthetic seismograms for the bedrock model, and if the local structure is known, realistic synthetic seismograms can be obtained for different ground conditions. Then, microzoning can be achieved by comparison of these two kind of synthetic seismograms. For this purpose, ground 
motion parameters should be extracted first. This procedure has been applied to the city of Rome [10]; an a-priori geotechnical zonation is used as a basis for a ground motion characterisation, in terms of response spectra ratio (RSR) and other parameters pertinent for the seismic microzoning. Another variant has been applied by Alvarez et al. [11], who made the microzonation by classifying the RSR curves calculated at sites distributed over the city plain, using geological data as auxiliary for the tracing of the borders between different zones. The theoretical principles of this methodology are presented by Panza et al. in Ref. [12], and the results obtained in the application of these principles to the seismic microzoning of 14 cities worldwide are summarised in Ref. [13].

The purpose of this paper is to make a microzoning, through a classification procedure of several relative ground motion quantities, extracted from synthetic seismograms. The flow chart of the microzonation procedure is shown in Fig. 1. The synthetic signals in the bedrock anelastic structure are generated by the modal summation approach [13-16]. The waveforms along the local, laterally varying anelastic structure are computed using a finite difference scheme applied to the local structure, combined with modal summation $[17,18]$. This procedure is known as the "hybrid approach". The case study is Santiago de Cuba, one of the first cities founded by Spanish in America (1508), on the south-eastern coast of Cuba island (in a protected deep water bay), that is exposed to a moderate seismic hazard. The first report of a felt earthquake is from 1578, and from its foundation to the present day it had experienced 5 shakings of intensity VIII and 2 of intensity IX in the MSK scale. From the macroseismic data, the magnitudes of these earthquakes have been estimated between 6.8 and 7.6. These values together with the low magnitude earthquakes in the Oriente fault zone give a good basis to consider a scenario earthquake of magnitude 7 , south of the city, at about $30 \mathrm{Km}$ distance off the coast [19]. The city has been the object of several microzoning studies, using classical Soviet school methodology [20,21] and some GIS based methodological variants [22, 23], as well as modelling of P-SV and SH waves [11, 19].

\section{Ground motion parameters}

The target of seismic microzoning is to represent in a map the relative variation of the expected seismic ground motion as a function of soil conditions. Traditionally it is accomplished in terms of the parameter $\Delta \mathrm{I}$ or of the transfer functions, related to a reference soil or a reference site. If the reference soil or the reference site is fixed as the regional bedrock structure, then a large number of relative quantities can be calculated from synthetic data.

In earthquake engineering, among others, peak values of displacement (PGD), velocity (PGV) and acceleration (PGA), design ground acceleration (DGA) and Arias intensity $\left(\mathrm{I}_{\mathrm{A}}\right)$ are often used. For all these quantities (generally indicated with $X$ in eq. (1)) it is possible to calculate the ratio, $X R$, 
between the values computed in the laterally varying medium, $\mathrm{X}_{2 \mathrm{D}}$, and these computed in the bedrock model $\mathrm{X}_{1 \mathrm{D}}$ :

$$
\mathrm{XR}=\mathrm{X}_{2 \mathrm{D}} / \mathrm{X}_{1 \mathrm{D}}
$$

We will consider the cases $X R=\left(P G D R, P G V R, P G A R, D G A R, I_{A} R\right)$.

The use of the elastic response spectra ratio (RSR), a function defined as:

$$
R S R(f)=R_{2 D}(f) / R S_{1 D}(f)
$$

where $R S_{2 D}$ and $R S_{1 D}$ are the elastic response spectra, of the $2 \mathrm{D}$ and $1 \mathrm{D}$ signals respectively, calculated for a viscous damping of $5 \%$, has been proved to be very useful for microzoning purposes $[10,11,13]$.

In the 90ties in earthquake engineering it has been introduced the use of the earthquake input energy spectrum $\left(\mathrm{E}_{\mathrm{I}}\right)$, a function defined as:

$$
\frac{E_{1}(T, v, \mu)}{m}=\int \ddot{u}_{t} d u_{g}=\int \ddot{u}_{t} \dot{u}_{g} d t
$$

where $u_{g}$ is the input seismogram (i.e. the earthquake ground displacement), $u_{t}$ is the absolute displacement $u_{t}(t)=u(t)+u_{g}(t)$, and $u(t)$ is the solution of the single degree of freedom (SDOF) problem under the action of an earthquake input $\mathrm{u}_{\mathrm{g}}[24,25]$. The structure is characterised by the parameters $v$ that corresponds to viscous damping constant and $\mu$ that represents displacement ductility. In the following $E_{\mathrm{I}} / \mathrm{m}$ will be called $E_{\mathrm{l}}$, like in $[24,25]$. This function, for a viscous damping of $5 \%$ is plotted in the $\left(T, E_{I}\right)$ plane and a new variable $\left(\mathrm{AE}_{\mathrm{I}}\right)$ is defined: the area enclosed by the elastic input energy spectrum in the interval of periods between 0.05 and 4.0 seconds.

$$
A E_{1}=\int_{005}^{40} E_{1}(v=5 \%, T) d T
$$

Equations (3a) and (3b), may be considered a global hazard index in energy terms [25] as it considers the influence of the energy demand in the whole period range, and have been successfully used for the characterisation of site-dependent seismic hazard [26]. The value of $\mu$ separates two different cases, the elastic $(\mu=1)$, for which remain the use of symbols $E_{I}$ and $\mathrm{AE}_{\mathrm{I}}$ and the anelastic $(\mu>1)$, that is expressed trough $\mathrm{E}_{\mathrm{I}} \mu$ and $\mathrm{AE}_{\mathrm{I}} \mu$ [27]. Let us define a new function, the elastic earthquake input energy spectra ratio $\left(E_{I} R\right)$ :

$$
\mathrm{E}_{\mathrm{I}} \mathrm{R}(\mathrm{f})=\mathrm{E}_{I 2 D}(\mathrm{f}) / \mathrm{E}_{I D D}(\mathrm{f})
$$

where $E_{12 D}$ and $E_{I D D}$ are the mean elastic earthquake input energy spectra $\left(E_{1}\right)$ for the laterally varying structure and the bedrock model, respectively. The use of the frequency, instead of the period that appears in the definition (3a), makes it possible the direct comparison of $E_{\mathrm{l}} R(f)$ with RSR(f).

Additionally, we can define $\mathrm{AE}_{\mathrm{I}} \mathrm{R}$, i.e. the ratio between the areas under the curves of $\mathrm{E}_{\mathrm{I}}$ :

$$
A E_{I} R(f)=A E_{12 D}(f) / A E_{I 1 D}(f)
$$


where $\mathrm{AE}_{12 D}$ and $\mathrm{AE}_{11 D}$ are the corresponding values the areas under the curves of $\mathrm{E}_{\mathrm{I}}$ for the laterally varying structure and the bedrock model, respectively.

\section{Data}

The regional structural model (until $110 \mathrm{Km}$ of depth) has been constructed, using geophysical studies [28, 29], and tomographic inversions [30, 31] (Fig. 2) and it has been used to calculate the bedrock P - SV and SH waves seismograms by modal summation until a maximum frequency of 10 Hz. Six 2D profiles, that cross the entire basin where Santiago de Cuba is located, have been constructed using borehole data. In Fig. 3a their traces are shown over a simplified version of the geological map of Medina et al. [32] of Santiago de Cuba basin. In Fig. 3b the corresponding crosssections are shown. The data about the mechanical properties $(\mathrm{P}-$ and $\mathrm{S}$-waves velocities and quality factors) of the strata (see Table 1) were taken from the literature $[4,33,34]$, and correspond to direct measurements made on similar soils in other places in Cuba, as no local measurements are available. A brief discussion about the geological setting of Santiago de Cuba basin and the data about its subsurface geology can be found in Ref. [11].

\section{Synthetic seismograms and derived parameters}

The complete set of seismograms of $\mathrm{P}-\mathrm{SV}$ and $\mathrm{SH}$ - waves for displacement, velocity and acceleration have been computed, at sites along the six profiles, by the hybrid approach $[17,18]$ considering a maximum frequency of $5 \mathrm{~Hz}$. Along each profile, the sites are on the free surface, with a constant spacing of $180 \mathrm{~m}$. We considered a point source with seismic moment $\mathrm{M}_{0}=1.0 \times 10^{13} \mathrm{~N}-\mathrm{m}$, focal depth $\mathrm{h}=20 \mathrm{Km}$, and focal mechanism: dip $=21^{\circ}$, azimuth $=100^{\circ}$ and rake $=21^{\circ}$. The computations were made twice, once considering the complex 2D structures, formed by the regional structure and the embedded in it detailed $2 \mathrm{D}$ profiles, and the second considering the uniform bedrock model only. As it was pointed out in the introduction, this dual calculation is important for microzoning purposes, because it allows us to calculate the variations of the earthquake ground motion, relative to the bedrock, i.e. the real site increment against the reference site. In our case, we do not have the quite common problem of selecting the reference site, because it is formed by the rock basement. The "elementary" seismograms have been scaled, in the frequency domain [35], for the scenario earthquake of magnitude $\left(M_{S}=7\right)$ by using the scaling law of Gusev [36], as reported by Aki [37]. The design ground acceleration (DGA) is obtained following the procedure defined by Panza et al. [35] using the design response spectra of the Cuban building code [38] for soils of type S1. The scaled seismograms (e.g. see Fig. 4) have been used for calculating the earthquake input energy spectrum $E_{1}$ and the corresponding $A E_{1}$ that turn out to be a 
little underestimated, since our integral begins at $T=0.2 \mathrm{sec}$. instead of $0.05 \mathrm{sec}$, as defined in ( $3 \mathrm{~b}$ ). Nevertheless, since we are interested in relative values, our choice of the integration interval does not affect our conclusions.

All the relative quantities above defined plus the maximum values of the functions $R S R$ and $E_{\mathrm{I}} R$ $\left(R S R_{\max }, E_{l} R_{\max }\right)$ and the frequencies at which these maxims occur $\left[f\left(R S R_{\max }\right), f\left(E_{l} R_{\max }\right)\right]$ have been plotted for each profile (an example is given in Fig. 5). Additionally we have drawn the plots of the functions $\operatorname{RSR}(f, x)$ and $\log \left[E_{I} R(f, x)\right]$ were " $x$ " is the epicentral distance to the site, formed by the original RSR(f) and $E_{l} R(f)$ evaluated in each of the sites considered. Examples are shown in Fig. 6 for RSR (together with the profile structure plot) and Fig. 7 for $\log \left[E_{I} R\right]$.

\section{Ground motion parameters classification}

\section{a) Single valued parameters}

The data shown in Fig. 5 correspond to the all the sites along profile p3 (see Fig. 3a) in which the synthetic seismograms have been calculated (radial component). The same has been done for all the profiles, for a total of 352 sites, and for the three components of motion. Since we do not observe, in general, a high variability of the curves, like the ones given in Fig. 5, in nearby sites, we decided, without a significant loss of information, to decimate (every 3 points) the available sites, which resulted in 115 sites, $560 \mathrm{~m}$ apart, along the profiles. In the following the analysis will be limited to the decimated set of signals.

The data for the 10 single-valued ground motion parameters [PGDR, PGVR, PGAR, DGAR, $\mathrm{I}_{\mathrm{A}} \mathrm{R}$, $\left.R_{S R} \max , E_{I} R_{\max }, A E_{I} R, f\left(R S R_{\max }\right), f\left(E_{I} R_{\max }\right)\right]$ has been divided into three sets, one for each component of motion, P-SV vertical, P-SV radial and SH (transverse). In order to select the variables to be used in the classification, a non-parametric correlation analysis between the different ground motion parameters has been made for each set. Because of the high values of $E_{1} R_{\max }$ present in the vertical component, its logarithm is used. The Spearman rank-order correlation and the Kendall's $\tau$ were tested. The hypothesis of independence of variables is rejected for all combinations of variables except when at least one of the variables is $f\left(R S R_{\max }\right)$ or $f\left(E_{I} R_{\max }\right)$ for the radial and transverse components, at a significance level of $10^{-4}$. The above is true also for the vertical component, and in addition the hypothesis of independence with respect to all other variables holds for $\log \left(E_{I} R_{\max }\right)$ and $A E_{I} R$ too. This is a consequence of the presence of some isolated very high values of these variables (outliers) and we decided not to take them into account because they don't allow a clear classification. With this exception, we have only 3 really independent variables that can be used for classification: the frequencies of the maxims of $f\left(R S R_{\max }\right)$ and $f\left(E_{l} R_{\max }\right)$, and one of the remaining eight, let's say, the maximum velocity ratio 
PGVR. Three sets of values are formed, one for each of the ground motion components.

\section{b) $\operatorname{RSR}(f)$ and $E_{I} R(f)$ functions}

In a previous paper [11] the classification of the function $\operatorname{RSR}(f)$ for the transverse component at $f_{\max }=1 \mathrm{~Hz}$ along 4 profiles have been used for microzoning purposes of Santiago de Cuba . These results, while limited, have shown the applicability of the method. At present we have 6 functions ( 3 components for $R S R(f)$ and 3 components for $\mathrm{E}_{[} R(f)$ evaluated for the 352 selected sites that can be used for classification. The same space sampling as in the case of single valued ground motion parameters is used, justified by the slow spatial variation of $R S R(f, x)$ and $E_{[} R(f, x)$. The functions are frequency sampled with 20 points uniformly distributed between $0.39 \mathrm{~Hz}$ and $4.95 \mathrm{~Hz}$. Six sets of values are formed, one per function and component.

\section{c) Final microzoning}

The process of classification of the nine sets of values results in a subdivision of the sites in groups that in general can be considered different. Seismic microzoning is characterised by generalisation and smoothing. Therefore, these groups should be as few as possible, and nearly corresponding groups should be merged together. At the end of the process every site will be characterised by 9 numbers that represent the group to which it belongs in each set. These data are used as input for a new classification, and as a result a new grouping of sites is done. Each group corresponds to a quasi-uniform behaviour of soils in terms of ground motion parameters and RSR(f) and $E_{I} R(f)$ functions. These groups define the final microzoning.

\section{d) Method of classification}

For the classification of ground motion parameters and functions, as well as for the final microzoning, an extension of the non-supervised logical-combinatorial algorithms included in PROGNOSIS system [39] has been tested. The extension is due to Pico [40] and allows us the interactive selection of the similarity levels at which the partition in groups of the initial sample will be done. Two main algorithms were used: compact sets and connected sets [40].

The selected algorithms start from the general conditions:

- Let the site " $j$ " be the object " $O_{j}$ ". An object is described in term of variables " $x_{l}\left(O_{j}\right)$ ", $i=1, n$.

- Let $S\left(O_{b}, O_{J}\right)$ be the similarity function between objects $O_{l}$ and $O_{J}, S\left(O_{b}, O_{J}\right)$ will be defined below. Two objects $O_{\imath}$ and $O_{J}$ are $\beta_{o}$-similar, if and only if $S\left(O_{l}, O_{J}\right) \geq \beta_{o}$, where $\beta_{o}$, the level of the classification, is between 0 and 1 .

- An object belongs to a connected set if all its $\beta_{o}$ - similar objects belong to this set.

- An object belongs to a compact set if the most $\beta_{o}$ - similar to it belongs to this set too, or if it is the most similar to another object belonging to the set. 
- The compact sets or the connected sets are graphically represented in a dendrogram (Fig. 8), where the different levels represent the $\beta_{o}$-similarity, which can be used to build groups. Selecting interactively, over this scheme, a level $\beta_{o}$, a particular partition in $\beta_{o}$-compact sets or in $\beta_{o}$ - connected sets can be obtained [40].

- A unique tree forms the dendrogram for the connected sets, i.e.; there is a $\beta_{o}$ level such that all the objects are connected. Besides, the dendrogram for the compact sets is, in general, formed by several isolated trees; i.e., while reducing the level $\beta_{o}$, the number of independent groups cannot be reduced below a certain limit. This behaviour is due to the fact that in the case of compact sets, the condition of connectivity between objects is more stringent than in the case of the connected ones.

- The procedure starts by determining the main $\beta_{o}$-compact sets or $\beta_{o}$-connected sets; then, some of the sets can be subdivided using additional criteria, and the average curve for each final set is calculated.

The initial settings for the classification process depend on the sample characteristics. 20 equally spaced frequency samples, i.e. $f_{t},(i=1,20)$, are taken for the functions $\operatorname{RSR}(f)$ and $\mathrm{E}_{\mathrm{I}} \mathrm{R}(\mathrm{f})$ and correspond to the variables $x_{i}$. In the case of ground motion parameters, the variables $x_{i}$ are the selected parameters for the classification $(i=1,3)$, while for the final microzoning the variables $x_{i}$ are the results of the classification of the original sets $(i=1,9)$ (integer numbers corresponding to the coding used in those classifications). The calculus of the similarity functions $S\left(O_{v}, O_{J}\right)$ is done as follows:

- In the case of connected sets, used for the ground motion parameters, the comparison criterion for a variable $x_{t}$ is the function $C_{t}$, defined as:

$$
C_{t}\left[x_{t}\left(O_{1}\right), x_{t}\left(O_{1}\right)\right]=1-\frac{\left|x_{t}\left(O_{1}\right)-x_{t}\left(O_{1}\right)\right|}{\max \left(x_{t}\right)-\min \left(x_{t}\right)}
$$

where $\max \left(x_{t}\right)$ and $\min \left(x_{t}\right)$ are the extremes of the variable $x_{t}$ over all the objects.

- In the case of compact sets, used for RSR and $E_{I} R$ curves, the comparison criterion for a variable $x_{t}$ is:

$$
C_{t}\left[x_{t}\left(O_{1}\right), x_{t}\left(O_{j}\right)\right]=\left\{\begin{array}{ccc}
1 & \text { if } & \left|x_{t}\left(O_{1}\right)-x_{t}\left(O_{j}\right)\right| \leq \varepsilon_{t} \\
0 & \text { elsewhere }
\end{array}\right.
$$

where the $\mathcal{E}_{t}$ have been selected as $0.1 *\left[\max \left(\mathrm{x}_{\mathrm{t}}\right)-\min \left(\mathrm{x}_{\mathrm{t}}\right)\right]$

- In the case of microzoning, the values of the variables are integer numbers, and the comparison is made by means of the simple equality:

$$
C_{t}\left[x_{t}\left(O_{1}\right), x_{t}\left(O_{1}\right)\right]=\left\{\begin{array}{lcc}
1 & \text { if } & x_{1}\left(O_{1}\right)=x_{1}\left(O_{1}\right) \\
0 & \text { elsewhere }
\end{array}\right.
$$


- The similarity between objects in all the cases is calculated by the formula:

$$
S\left(O_{1}, O_{k}\right)=1 / n \sum_{t=1}^{n} C_{t}\left[x_{t}\left(O_{1}\right), x_{t}\left(O_{k}\right)\right]
$$

where $\mathrm{n}$ is the number of considered variables and $C_{t}$ the criterion defined above.

\section{Results}

The 3 sets of the RSR(f) function and the 3 sets of the $\mathrm{E}_{\mathrm{I}} \mathrm{R}(\mathrm{f})$ function have been classified in compact sets. The results of this classification are six maps with the coding of the obtained groups and the corresponding plots of the average functions for each group (an example is given in Fig. $9 a, b$ for the transverse $E_{I} R(f)$ ). In Fig $9 a$ it is seen that nearly coincident sites belonging to different profiles are not always classified in the same group. This is due to the fact that waveforms in laterally varying media do not depend only on the structure under the site where they are analysed, but on the source-site path of the bi-dimensional structure (e.g. see Ref. [41]).

The 3 sets for the ground motion parameters have been classified in connected sets. An example is given in Fig. 10 for the radial component of ground motion. In Fig. 10a a map is shown with the coding of the classification, and in Fig. 10b all the data belonging to the groups in which this set is classified are plotted.

At this stage, we have 9 different maps (one for each initial set of values) with a coding that represents how the particular characteristics of the ground motion vary in space. Each map could be selected to do the microzoning. We have no elements to choose the best one for doing the microzoning, and therefore we have decided to use all the maps together. For doing so, the coding defined in each of the nine maps is considered as a new initial sample to be classified in connected sets too, leading to a map with the final microzoning coding (Fig. 11).

\section{Discussion}

The influence of local soil conditions on earthquake signals is clearly seen from the signals shown in Fig. 4. The relative ground motion parameters, shown in Fig. 5, give a good characterisation of the influence of soil properties on earthquake ground motion. The complexity of the problem is evident from the fact that the signals vary not only from one profile to another, but for each profile, from one component of motion to the other. The RSR(f, $x$ ) and $\log \left[\mathrm{E}_{\mathrm{I}} \mathrm{R}(\mathrm{f}, \mathrm{x})\right]$ plots (Fig. 6 and Fig. 7 respectively) in a gross way show the same general characteristics.

The problem of selecting the best way to characterise the earthquake seismic ground motion is not solved until now. The analysis of the relative ground motion parameters and RSR and $E_{\mathrm{I}} \mathrm{R}$ functions evidences the impossibility to select one of them for microzoning purposes; therefore our decision 
to make a classification using all the data. The classification had to be done in two parts: (a) each data set (three $R S R$, three $E_{l} R$, three ground motion parameters) has been independently classified; (b) the results of step (a) have been used as input for another classification that leads to the final microzonation. The maps of the kind presented in Figs. 9a and 10a cannot be combined by means of a straightforward procedure. Again, the way for solving the problem has been to classify these preliminary results. Rather than the spatial distribution of a single parameter, as is usual in microzoning maps, the map of Fig. 11 shows the spatial distribution of sites with quasihomogeneous behaviour. Each group identified after the final classification is not characterised by a common value of a given ground motion parameter, taken as a criterion for microzoning. Instead, the sites belonging to each group are characterised by a given degree of similarity among the nine initially classified sets of values that describe the ground-motion characteristics. The sites have similar, but not equal behaviour in response to seismic load. The degree of similarity used to define the groups is measured by the similarity between the objects defined in eqs. $(8,9)$. The average similarity of the sites represented in the map of Fig. 11 is 0.66 , which means, according with eq. (9), that 6 out of the 9 variables are equal. Nevertheless, for some of the groups shown in Fig. 11 (those identified with letters $\mathrm{A}-\mathrm{L}$ ) the similarity is 0.77 , which corresponds to 7 equal variables, and there is only one group with similarity of 0.55 (identified with letter S) that corresponds to only 5 equal variables.

Seismic microzoning requires a division in zones, of the studied region. If we analyse the site spatial distribution in Fig. 11, it is evident that for the studied area it is not possible to produce a map, but if we add other information to our results we can make a microzoning scheme. Our choice has been to use the geological map of Santiago de Cuba basin of Medina et al. [32] (see Fig. 3a) and the microzoning scheme proposed in [11]. In Fig. 12 we present the final microzonation. It has been constructed by tracing the boundaries between zones following, as close as possible, the limits between the geological formations, and avoiding to make additional generalisations of the results of classification. For each zone of Fig. 12, we calculated average single valued quantities (see Table 2) and average $\operatorname{RSR}(f)$ and $\mathrm{E}_{\mathrm{I}} \mathrm{R}(\mathrm{f})$ functions (Fig. 13), obtained from the signals associated with the sites belonging to each zone.

\section{Conclusions}

Earthquake ground motion has been characterised by means of several relative (soil/bedrock) single valued quantities (PGDR, PGVR, PGAR, DGAR, $I_{A} R$, etc.), by the response spectra ratio RSR( $f$ ) and by the elastic energy input ratio $E_{I} R(f)$ (defined in this paper), extracted from synthetic data. 
The seismic microzoning has been done by classifying these data using two logical combinatory algorithms: connected sets and compact sets [40]. Data were sampled at 105 sites distributed along 6 profiles that sample the study area.

The classification process has been accomplished in two steps. The original 9 data sets (RSR and $E_{\mathrm{I}} \mathrm{R}$ functions, and single-valued ground motion parameters, for the different components of motion - radial, transverse and vertical) are classified at first. In this way, the spatial distribution of the soil behaviour as a function of the component of motion is obtained. The results of this classification are used as input for a further classification to define the spatial distribution of the sites with a quasihomogeneous integral ground motion behaviour. The latter classification is combined with the geological surface data available to produce a microzoning scheme for Santiago de Cuba basin.

\section{References}

1. Kanai, K., Tanaka, T. Measurement of the microtremor. Bull. Earthquake Res. Inst. 1954; 32:199-209.

2. Medvedev, S. M.: Engineering seismology (in Russian). Moscow: Nauka, 1962.

3. Medvedev, S. M. Seismic microzoning (in Russian). Moscow: Nauka, 1977.

4. Pavlov O.Y. (ed.). Seismic microzoning (in Russian). Moscow: Nauka, 1984.

5. Borcherdt, R.D. Effects of local geology near San Francisco Bay. Bull. Seis. Soc. Am. 1970; 60:29-61.

6. Murphy, J.R., Hewlett, R.A. Analysis of seismic response in the city of Las Vegas, Nevada: a preliminary microzonation. Bull. Seism. Soc. Am. 1975; 65:1575-1598.

7. Hays, W.W. Procedures for estimating earthquake ground motions. Geological Survey Professional Paper 1114. Washington, USA: Government Print Office, 1980.

8. Nakamura, K.: Inferences of seismic responses of surficial layer based on microtremor measurement (in Japanese). Quarterly Report on Railroad Research, Vol. 4, Railway Technical Research Institute; 1988. p. 18-27.

9. Bard, P. Microtremor measurements: A tool for site effect estimation? In: Irikura, Kudo, Okada, Sasatani (ed.): The effects of surface geology on seismic motion; 1999. p. 12511279.

10. Fäh, D., Iodice, C., Suhadolc, P., Panza, G.F. Application of numerical simulations for a tentative seismic microzonation of the city of Rome. Ann. Geofis. 1995; 38:607-616.

11. Alvarez, L., García, J., Vaccari, F., Panza, G.F., González, B., Reyes, C., Fernández, B., Pico, R., Zapata, J.A., Arango, A. Seismic microzoning of Santiago de Cuba: An approach 
by SH waves modelling. ICTP Preprint No. IC/2002/63; 2002 (submitted to Pure and Applied Geophysics).

12. Panza, G. F., Romanelli, F., Vaccari, F. Seismic wave propagation in laterally heterogeneous anelastic media: theory and applications to the seismic zonation, Advances in Geophysics No. 43, Academic Press; 2000. p. 1-95.

13. Panza , G. F. , Alvarez, L., Aoudia, A., Ayadi, A., Benhallou, H., Benouar, D., Bus, Z., Chen, Y-T., Cioflan, C., Ding, Z., El-Sayed, A., García, J., Garofalo, B., Gorshkov, A., Gribovszki, K., Harbi, A., Hatzidimitriou, P., Herak, M., Kouteva, M., Kuznetzov, I., Lokmer, I., Maouche, S., Marmureanu, G., Matova, M., Natale, M., Nunziata, C., Parvez, I., Paskaleva, I., Pico, R., Radulian, M., Romanelli, F., Soloviev, A., Suhadolc, P., Szeidovitz, G., Triantafyllidis, P., Vaccari, F. Realistic Modeling of Seismic Input for Megacities and Large Urban Areas (the UNESCO/IUGS/IGCP project 414). Episodes 2002; 25:160-184.

14. Panza, G.F. Synthetic seismograms: the Rayleigh waves modal summation. J. Geophys. Res. 1985; 58:125 145.

15. Panza, G.F., Suhadolc, P. Complete strong motion synthetics. In: B. A. Bolt (ed.) Seismic Strong Motion Synthetics, Computational Techniques 4, Academic Press, Orlando, 1987. p. 153-204.

16. Florsch, N., Fäh, D., Suhadolc, P., Panza, G.F. Complete synthetic seismograms for highfrequency multimode SH-waves. Pure and Applied Geophysics 1991; 136:529-560.

17. Fäh, D.: A hybrid technique for the estimation of strong ground motion in sedimentary basins. Ph.D. Thesis, Nr. 9767, Swiss Fed. Inst. Technology, Zurich, 1992.

18. Fäh, D., Iodice, C., Suhadolc, P., Panza, G.F. A new method for the realistic estimation of seismic ground motion in megacities, the case of Rome. Earthquake Spectra 1993; 9:643668.

19. Alvarez, L., Vaccari, F., Panza, G.F., González, B.E. Modelling of ground motion in Santiago de Cuba City from earthquakes in Oriente fault seismic zone. Pure and Applied Geophysics 2001; 158:1763-1782.

20. González, B.E., Mirzoev, K.M., Chuy, T., Golubiatnikov, V.L., Lyskov, L.M., Zapata, J.A., Alvarez, H. Microzonación sísmica de la ciudad de Santiago de Cuba, Comunicaciones Científicas sobre Geofísica y Astronomía No. 15, Instituto de Geofísica y Astronomía, Academia de Ciencias de Cuba, 1989.

21. González, B.E. Estimación del efecto sísmico en la ciudad de Santiago de Cuba. Tesis en opción al grado de Candidato a Doctor en Ciencias Físicas, Instituto de Geofísica y Astronomía, La Habana; 1991.

22. Zapata, J.A. Utilización de variantes metodológicas de microzonificación sísmica en la 
ciudad de Santiago de Cuba. In: (Zapata, J.A. (ed.): Red de estaciones e investigaciones sismológicas en Cuba, La Habana, Editorial Academia, 2000. p. 88-112.

23. García, J., Arango, E., Zapata, J.A., Oliva, J., González, B., Fernández, B., Chuy, T., Reyes, C., Monnar, O. Mapa de riesgo sísmico de la ciudad de Santiago de Cuba. Report, Centro Nacional de Investigaciones Sismológicas, Santiago de Cuba, 2002.

24. Uang, C. M., Bertero, V. V.: Evaluation of seismic energy in structures. Earthquake Engineering and Structural Dynamics 1990; 19:77-90.

25. Decanini, L., Mollaioli, F. Formulation of Elastic Earthquake Input Energy Spectra. Earthquake Engineering and Structural Dynamics 1998; 27:1503-1522.

26. Panza, G.F., Cioflan, C., Kouteva, M., Paskaleva, I., Romanelli, F., Marmureanu, G. An innovative assessment of the seismic hazard from Vracea intermediate-depth earthquakes: case studies in Romania and Bulgaria. ICTP Preprint No. IC/2002/6; 2002.

27. Decanini, L., Mollaioli, F. An energy-based methodology for the assessment of seismic demand. Soil Dynamics and Earthquake Engineering 2001; 21:113-137.

28. Arriaza, G. Nuevos enfoques en la interpretación y procesamiento de las ondas refractadas para el estudio del basamento de Cuba. Tesis presentada en opción al grado científico de Doctor en Ciencias Geológicas. La Habana, 1998.

29. Orihuela, N., Cuevas, J. L. Modelaje sismogravimétrico de perfiles regionales del Caribe central. Revista Ingeniería, Universidad Central de Venezuela 1993; 8:55-73.

30. Van der Hilst, R. D. Tomography with P, PP and pP delay-time data and the threedimensional mantle structure below the Caribbean region. Ph.D. Thesis. University of Utrecht, 1990.

31. Moreno, B., Grandison, M., Atakan, K. Crustal velocity model along the southern Cuban margin: implications for the tectonic regime at an active plate boundary. Geophys. J. Int. $2002 ; 150: 1-14$.

32. Medina, A., Escobar, E., Ortíz, G. Ramírez, M., Díaz, L., Móndelo, F., Montejo, N., Diéguez, H., Guevara, T., Acosta, J. Reconocimiento geólogo-geofísico de la cuenca de Santiago de Cuba, con fines de riesgo sísmico. Report, Empresa Geominera de Oriente, Santiago de Cuba, 1999.

33. Ishihara, K., (chairman). The Technical Committee for earthquake Geotechnical Engineering (TC-4) of the International Society for Soil Mechanics and Foundation Engineering, Manual for Zonation on Seismic Geotechnical Hazards. The Japanese Society of Soil Mechanics and Foundation Engineering, 1993.

34. Berge-Thierry, C., Lussou, P., Hernández, B., Cotton E., Gariel, J.C. Computation of the strong motions during the 19995 Hyogoken-Nambu earthquake, combining the k-square 
spectral source model and the discrete wavenumber technique. In: Proceedings of the Second International Symposium on the Effects of Surface Geology on Seismic Motion, Yokohama, Japan, 1-3 December, 1998; Volume 3, The Effects of Surface Geology on Seismic Motion, Recent Progress and New Horizon on ESG Study, 1999. p. 1414-1424.

35. Panza, G.F., Vaccari, F., Costa, G., Suhadolc, P., Fäh, D. Seismic input modelling for zoning and microzoning. Earthquake Spectra 1966; 12:529-566.

36. Gusev, A.A. Descriptive statistical model of earthquake source radiation and its application to an estimation of short period strong motion. Geophys. J. Roy. Astron. Soc. 1983; 74:787800 .

37. Aki, K. Strong motion seismology. In: Erdik, M.Ö, Toksöz, M.N. (ed.): Strong Ground Motion Seismology, NATO ASI Series, Series C: Mathematical and Physical Sciences, vol. 204, D. Reidel Publishing Company, Dordrecht, 1987. p. 3-41.

38. Norma Cubana NC 46: 1999, Construcciones sismo resistentes. Requisitos básicos para el diseño y construcción, 3. Edición ICS: 91.080; 91.120.25. Ofícina Nacional de Normalización, Ciudad de La Habana, 1999.

39. Ruiz, J, Pico, R., López, R., Alaminos, C., Lazo, M., Baggiano, M., Barreto, E., Santana, A., Alvarez, L., Chuy, T. PROGNOSIS y sus aplicaciones a las geociencias. In: IBERAMIA92, III Congreso Iberoamericano de Inteligencia Artificial, Memorias. México: LIMUSA, 1992. p. 561-586.

40. Pico, R. Determinación del umbral de semejanza $\beta_{0}$ para los algoritmos de agrupamiento lógico-combinatorios, mediante el dendrograma de un algoritmo jerárquico. SIARP'99, IV Simposio Iberoamericano de Reconocimiento de Patrones. Memorias, 1999. p. 259-265.

41. Triantafyllidis, P., Suhadolc, P., Hatzidimitriou, D. Influence of source on 2D site effects. Geophys. Res. Lett. (in press). 
Table 1. Values of the mechanical parameters of the strata present in the profiles. The code corresponds to numbers in the legend of Fig. $3 b . \rho$-density, $v_{P}, v_{S}$ - velocities of $P$ and $S$ waves, $Q_{P}, Q_{S}$ - quality factors of $P$ and $S$ waves.

\begin{tabular}{|c|c|c|c|c|c|}
\hline Code & $\rho\left(\mathrm{g} / \mathrm{cm}^{3}\right)$ & $\mathbf{v}_{\mathbf{P}}(\mathbf{K m} / \mathbf{s})$ & $\mathbf{Q}_{\mathbf{P}}$ & $\mathbf{v}_{\mathbf{S}}(\mathbf{K m} / \mathbf{s})$ & $\mathbf{Q}_{\mathbf{S}}$ \\
\hline 1 & 2.3 & 2.5 & 200 & 1.4 & 100 \\
\hline 2 & 2.0 & 1.3 & 150 & 0.6 & 50 \\
\hline 3 & 2.1 & 2.4 & 350 & 0.8 & 15 \\
\hline 4 & 1.6 & 0.8 & 100 & 0.3 & 50 \\
\hline 5 & 1.8 & 1.2 & 100 & 0.35 & 50 \\
\hline 6 & 1.8 & 0.9 & 150 & 0.5 & 50 \\
\hline
\end{tabular}


Table 2. Average values, for the three components of motion, of the relative parameters (defined in formulae $1-5$ ) in the zones delimited in Fig. 12. Being relative values, they are adimensional.

a) Radial

\begin{tabular}{|c|c|c|c|c|c|c|c|c|}
\hline Zone & PGDR & PGVR & PGAR & DGAR & $\mathbf{I}_{\mathbf{A}} \mathbf{R}$ & $\mathbf{R S R}_{\max }$ & $\mathrm{AE}_{\mathbf{l}} \mathbf{R}$ & $\log \left(\mathbf{E}_{\mathrm{l}} \mathbf{R}\right)_{\max }$ \\
\hline 1 & 1.44 & 2.34 & 1.87 & 1.99 & 5.23 & 2.62 & 6.46 & 1.02 \\
\hline 2 & 1.52 & 2.73 & 2.01 & 2.63 & 9.44 & 4.13 & 11.30 & 1.29 \\
\hline 3 & 1.43 & 1.91 & 1.47 & 1.78 & 5.60 & 2.66 & 9.73 & 1.40 \\
\hline 4 & 2.06 & 3.96 & 2.79 & 5.16 & 44.44 & 8.71 & 75.19 & 2.45 \\
\hline 5 & 1.93 & 3.04 & 1.89 & 3.35 & 23.82 & 5.53 & 43.75 & 1.92 \\
\hline 6 & 1.69 & 3.25 & 2.64 & 3.19 & 28.59 & 5.78 & 28.66 & 1.74 \\
\hline 7 & 1.49 & 2.20 & 1.65 & 1.87 & 6.33 & 2.59 & 8.35 & 1.15 \\
\hline 8 & 1.25 & 2.03 & 1.83 & 2.37 & 10.06 & 3.21 & 10.53 & 1.20 \\
\hline 9 & 1.21 & 2.44 & 2.17 & 2.33 & 16.85 & 3.57 & 33.64 & 1.95 \\
\hline 10 & 1.43 & 2.35 & 2.17 & 2.38 & 15.95 & 3.69 & 53.43 & 2.12 \\
\hline 11 & 1.95 & 3.84 & 2.41 & 4.98 & 41.17 & 7.22 & 92.93 & 2.72 \\
\hline
\end{tabular}


b) Transverse

\begin{tabular}{|c|c|c|c|c|c|c|c|c|}
\hline Zone & PGDR & PGVR & PGAR & DGAR & $\mathbf{I}_{\mathbf{A}} \mathbf{R}$ & $\mathbf{R S R}_{\max }$ & $\mathbf{A E}_{\mathbf{1}} \mathbf{R}$ & $\log \left(E_{\mathbf{I}} \mathbf{R}\right)_{\max }$ \\
\hline 1 & 1.23 & 1.63 & 1.56 & 2.09 & 4.34 & 2.84 & 2.73 & 0.77 \\
\hline 2 & 1.24 & 1.18 & 1.50 & 2.34 & 6.19 & 3.71 & 2.88 & 1.08 \\
\hline 3 & 1.29 & 1.71 & 1.42 & 2.19 & 5.43 & 2.64 & 4.14 & 0.98 \\
\hline 4 & 1.32 & 1.96 & 1.90 & 4.56 & 23.29 & 6.13 & 11.83 & 1.75 \\
\hline 5 & 1.18 & 2.35 & 1.71 & 3.10 & 15.38 & 3.84 & 10.81 & 1.27 \\
\hline 6 & 1.44 & 1.99 & 2.50 & 3.88 & 25.53 & 6.37 & 10.48 & 1.69 \\
\hline 7 & 1.14 & 1.44 & 1.17 & 1.79 & 3.80 & 2.30 & 2.39 & 0.71 \\
\hline 8 & 1.14 & 1.31 & 1.45 & 1.86 & 5.13 & 2.26 & 2.74 & 0.77 \\
\hline 9 & 1.35 & 2.32 & 2.33 & 2.80 & 13.14 & 3.46 & 9.80 & 1.34 \\
\hline 10 & 1.23 & 1.59 & 2.06 & 2.91 & 12.55 & 4.16 & 6.53 & 1.30 \\
\hline 11 & 1.37 & 2.68 & 1.84 & 5.64 & 21.88 & 6.04 & 13.25 & 1.77 \\
\hline
\end{tabular}


c) Vertical

\begin{tabular}{|c|c|c|c|c|c|c|c|c|}
\hline Zone & PGDR & PGVR & PGAR & DGAR & $\mathbf{I}_{A} \mathbf{R}$ & $\mathbf{R S R}_{\max }$ & $\mathbf{A E}_{\mathbf{l}} \mathbf{R}$ & $\mathbf{l o g}\left(\mathbf{E}_{\mathbf{I}} \mathbf{R}\right)_{\max }$ \\
\hline 1 & 1.12 & 1.65 & 1.84 & 3.17 & 7.18 & 4.77 & 3.22 & 1.06 \\
\hline 2 & 0.95 & 1.59 & 1.43 & 2.43 & 5.58 & 2.97 & 3.15 & 0.85 \\
\hline 3 & 0.96 & 1.34 & 1.34 & 2.60 & 8.81 & 3.23 & 5.03 & 1.11 \\
\hline 4 & 1.00 & 1.69 & 1.71 & 4.29 & 23.91 & 5.19 & 11.75 & 1.60 \\
\hline 5 & 0.87 & 1.65 & 1.58 & 4.21 & 23.40 & 5.10 & 12.07 & 1.44 \\
\hline 6 & 0.89 & 1.11 & 1.14 & 2.57 & 13.44 & 3.80 & 6.03 & 1.19 \\
\hline 7 & 0.94 & 1.07 & 0.90 & 1.69 & 3.46 & 2.28 & 2.16 & 0.73 \\
\hline 9 & 0.88 & 1.17 & 1.19 & 1.79 & 3.49 & 2.35 & 2.31 & 0.71 \\
\hline 10 & 0.91 & 1.01 & 0.79 & 1.83 & 7.70 & 2.08 & 13.01 & 1.49 \\
\hline 11 & 1.04 & 1.18 & 1.18 & 2.22 & 15.76 & 3.41 & 14.99 & 1.62 \\
\hline
\end{tabular}




\section{Figure captions}

Fig. 1. Flow-chart of the microzonation procedure.

Fig. 2. Regional structural model

Fig. 3. a) Profiles traced over a simplified geological scheme of Santiago de Cuba basin (modified from [32]), 1 -sand and sandstones (Quaternary formations), 2-clays (Neogene), 3-marls (Neogene), 4-magmatic intrusions, 5-calcareous rocks and limestones (Neogene and Quaternary formations), 6 - rocks from El Cobre formation (Paleogene Volcanic Arc), 7 -faults. The ticks on the frame of the figure are $1 \mathrm{Km}$ apart, the left-low corner has coordinates $19.945^{\circ} \mathrm{N}$. and $75.897^{\circ}$ W.; b) Cross sections of the profiles. The numbering in the legend corresponds to different kind of soils, whose mechanical parameters are given in Table 1.

Fig. 4. Example of synthetic signals for a scenario earthquake of $M_{S}=7$ at a distance of about 30 $\mathrm{Km}$ from the beginning of the profile (the one labelled as "pc" in Fig. 3a,b), and at a depth of 20 $\mathrm{Km}$.

Fig. 5. Example of the variation of the considered relative ground motion parameters along a profile (the one labelled as "p3" in Fig. 2a,b). The $x$-axes represent the number of the sites along the profile.

Fig. 6. Relative response spectra (RSR) for the P-SV and SH waves as a function of frequency along the profile labelled "pb" in Fig. 3a,b. The uppermost $210 \mathrm{~m}$ of the local model along the profile is plotted below the panels of RSR. The numbers along the $\mathrm{x}$-axes correspond to the epicentral distance.

Fig. 7. Logarithm of the relative elastic energy input spectra $\left(E_{I} R\right)$ of the P-SV and SH waves as a function of frequency along the profile labelled "pb" in Fig. 3a,b. The numbers along the $\mathrm{x}$-axes correspond to the epicentral distance.

Fig. 8. Examples of the grouping of objects with the used classification algorithms. For the same input data, the grouping in connected sets (a) and in compact sets (b) are shown. In the y-axes are shown the values of the similarity function, while in the $\mathrm{x}$-axes are shown the ordinal number in the input data of the objects.

Fig. 9. Results of the classification using $\log \left[E_{l} R\right]$ of the transverse component of motion. (a) Map representation of the results of the classification of all the curves. The ticks on the frame of the figure are $0.5 \mathrm{Km}$ apart, the left-low corner has coordinates $19.945^{\circ} \mathrm{N}$. and $75.897^{\circ} \mathrm{W}$; (b) Average $\log \left[E_{\mathrm{I}} R(f)\right]$ curves for each of the groups.

Fig. 10. Results of the classification using the ground motion parameters of the radial component of motion. (a) Map representation of the results of the classification of all the curves. The ticks on the frame of the figure are $0.5 \mathrm{Km}$ apart, the left-low corner has coordinates $19.945^{\circ} \mathrm{N}$. and $75.897^{\circ}$ 
W.; (b) plot of the groups (A-G) in which the initial sample has been classified. In the $x$-axis, the value 1 corresponds to $P G V R, 2$ to $f\left(R S R_{\max }\right)$ and 3 to $f\left(E_{l} R_{\max }\right)$. The $y$-axis units are adimensional for 1 , and $\mathrm{Hz}$ for 2 and 3.

Fig. 11. Final classification. Map representation of the quasi-homogeneous groups to which the selected sites belong. The ticks on the frame of the figure are $0.5 \mathrm{Km}$ apart, the left-low corner has coordinates $19.945^{\circ} \mathrm{N}$. and $75.897^{\circ} \mathrm{W}$.

Fig. 12. Microzoning scheme of Santiago de Cuba. The different zones are delimited combining geological information and the result of the classification. The ticks on the frame of the figure are $0.5 \mathrm{Km}$ apart, the left-low corner has coordinates $19.945^{\circ} \mathrm{N}$. and $75.897^{\circ} \mathrm{W}$.

Fig. 13. Average curves of $R S R(f)$ and $\log \left[E_{[} R(f)\right]$ (radial, transverse and vertical component of motion) corresponding to each of the zones of the microzoning scheme. They are labelled accordingly to the numbers in Fig. 11. 


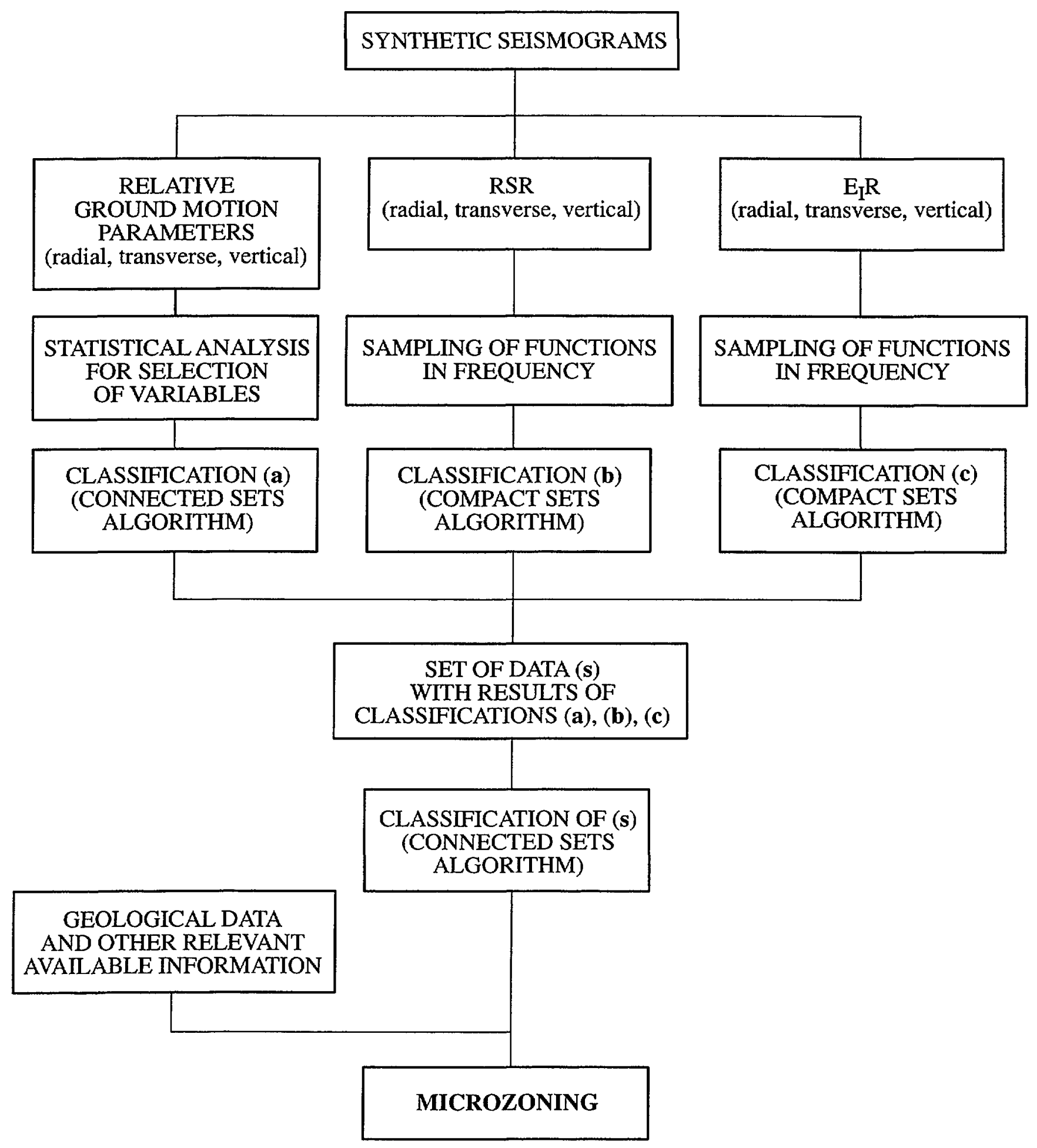

Fig.1. 

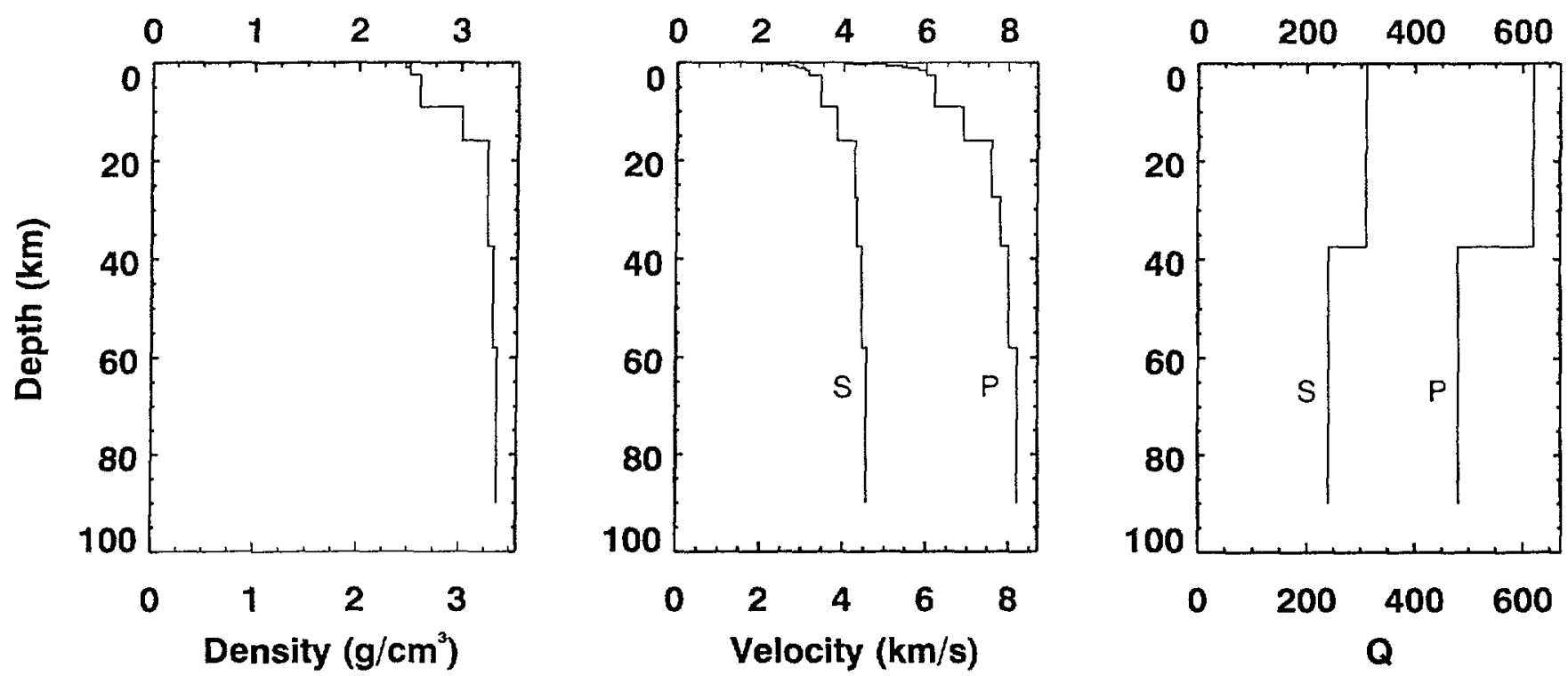

Fig. 2.
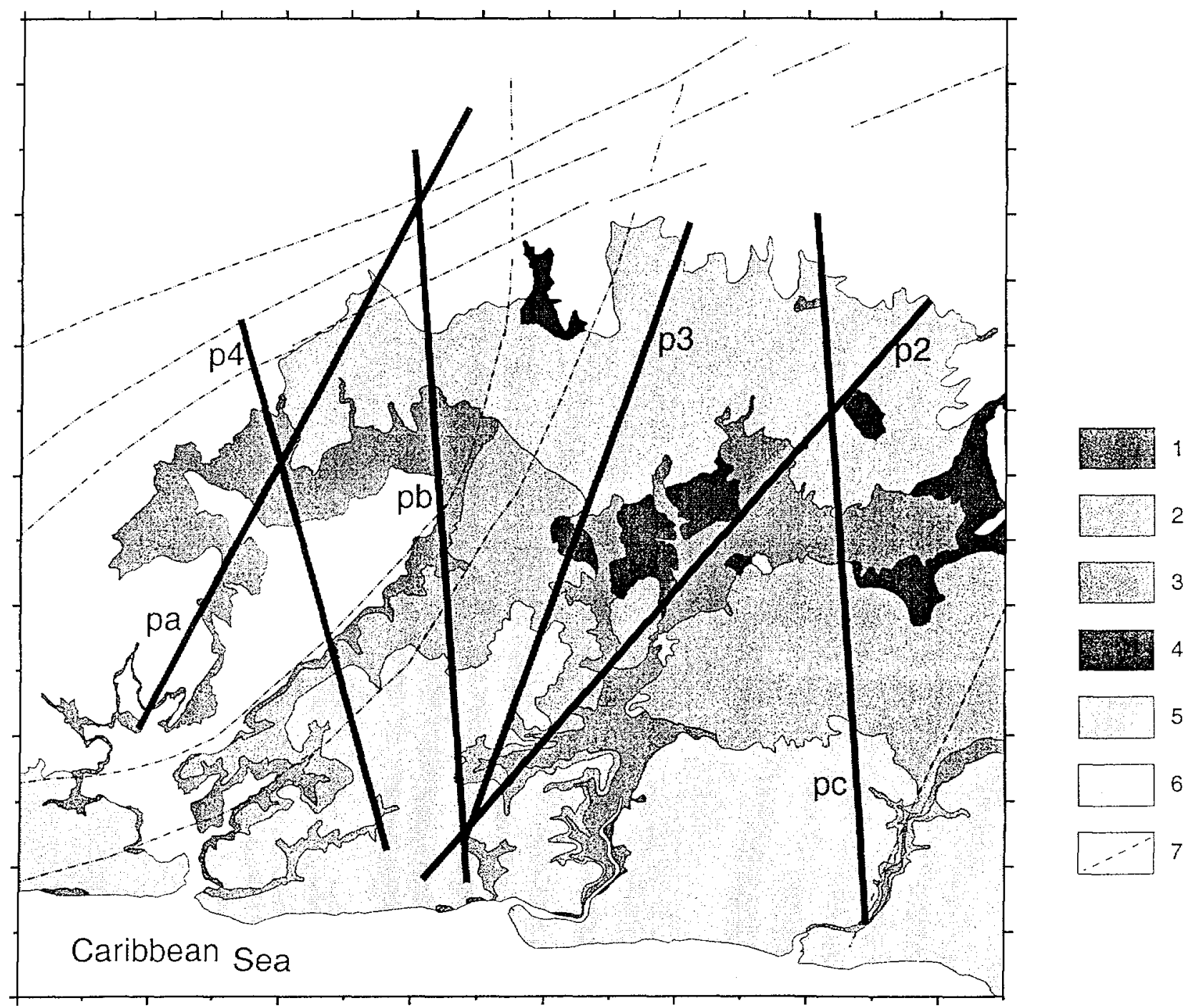

Fig.3a. 
pa

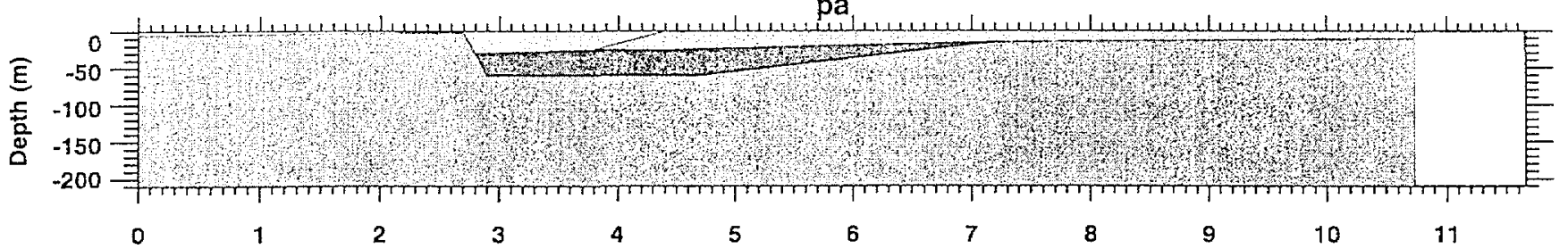

Distance $(\mathrm{Km})$

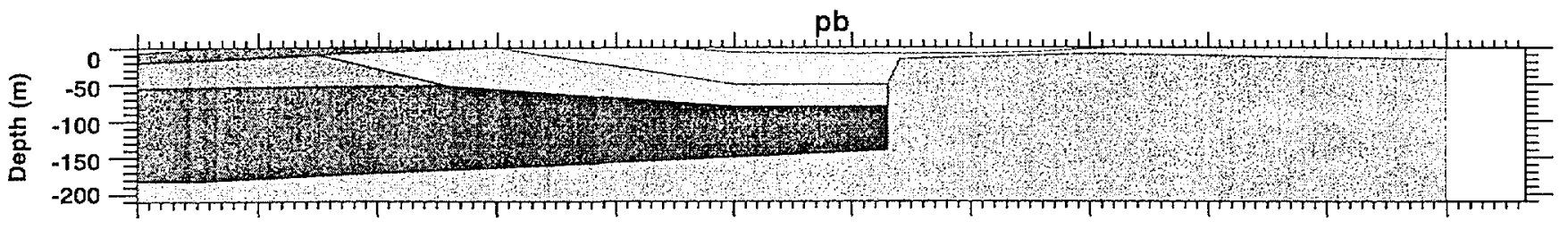

$\begin{array}{llllllllllll}0 & 1 & 2 & 3 & 4 & 5 & 6 & 7 & 8 & 9 & 10 & 11\end{array}$

Dlstance $(\mathrm{Km})$

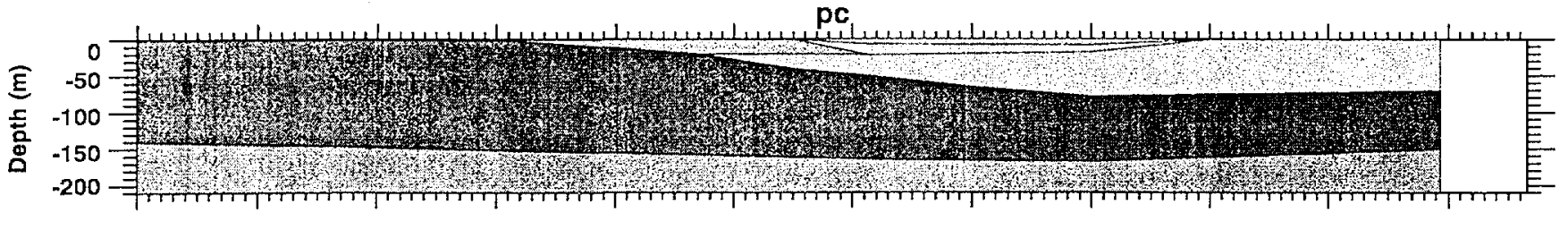

$\begin{array}{lllllllllll}0 & 1 & 2 & 3 & 4 & 5 & 6 & 7 & 8 & 10 & 11\end{array}$

P2

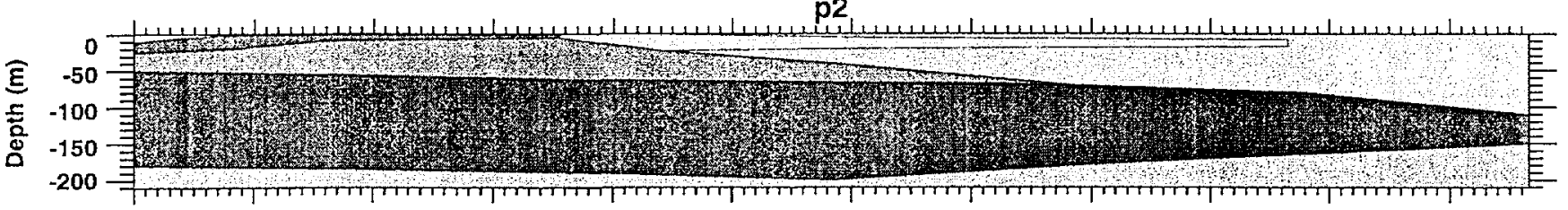

Distance $(\mathrm{Km})$

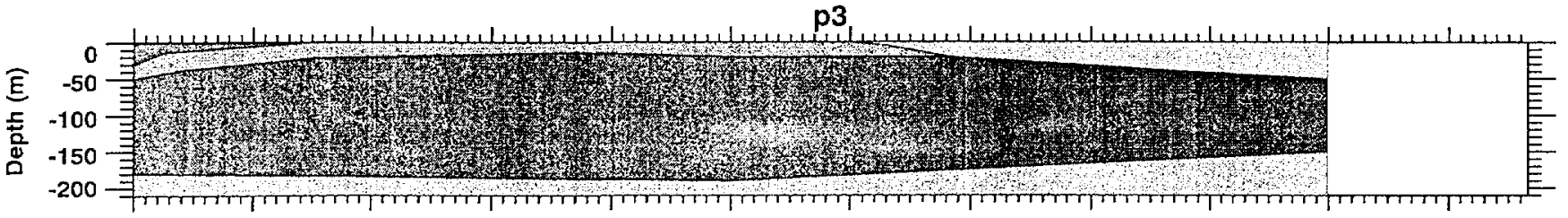

$\begin{array}{lllllllllllll}0 & 1 & 2 & 3 & 4 & 5 & 6 & 7 & 8 & 9 & 10 & 11\end{array}$

Distance $(\mathrm{Km})$

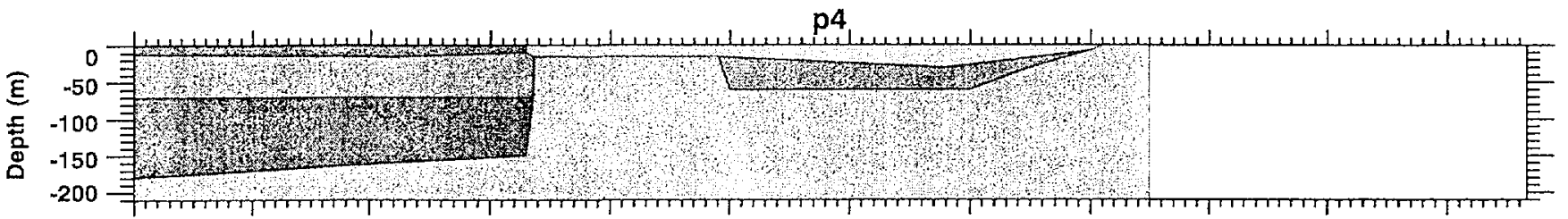

1

Distance $(\mathrm{Km})$

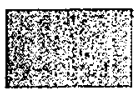

1

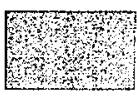

2

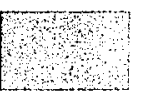

3

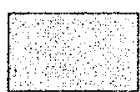

4

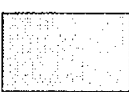

5

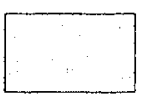

6

Fig. 3b. 

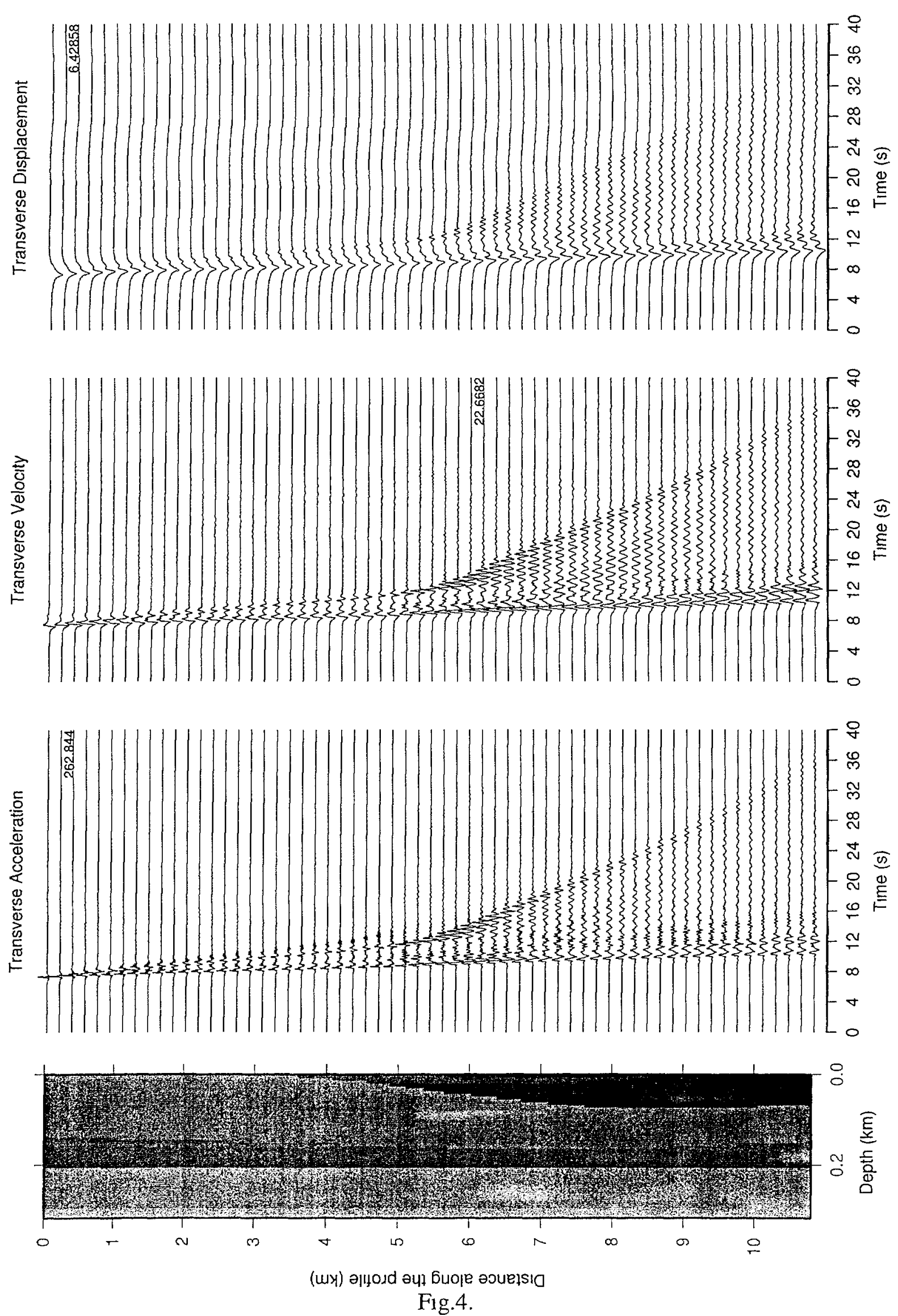

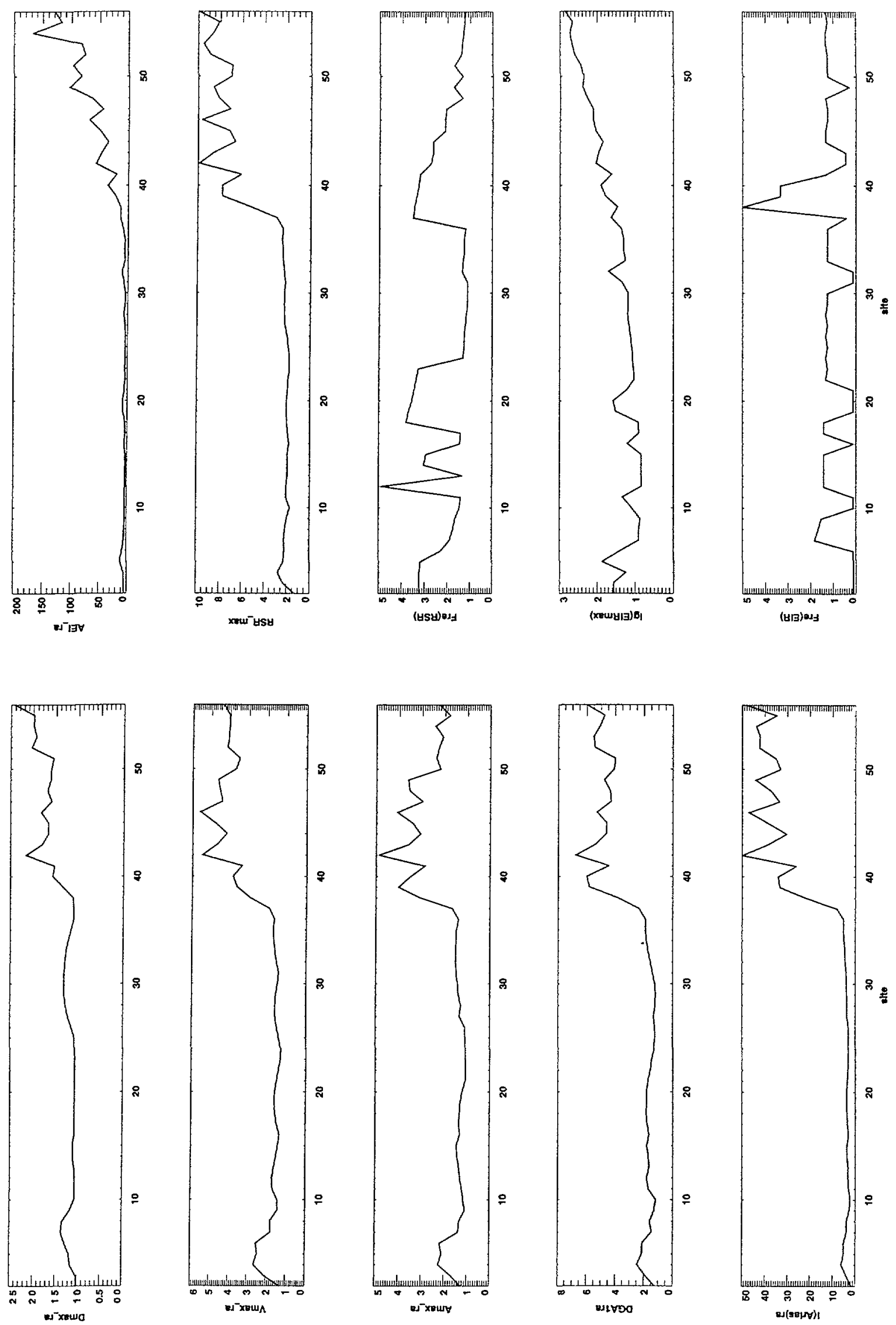

Fig. 5 
Distance from the source $(\mathrm{km})$
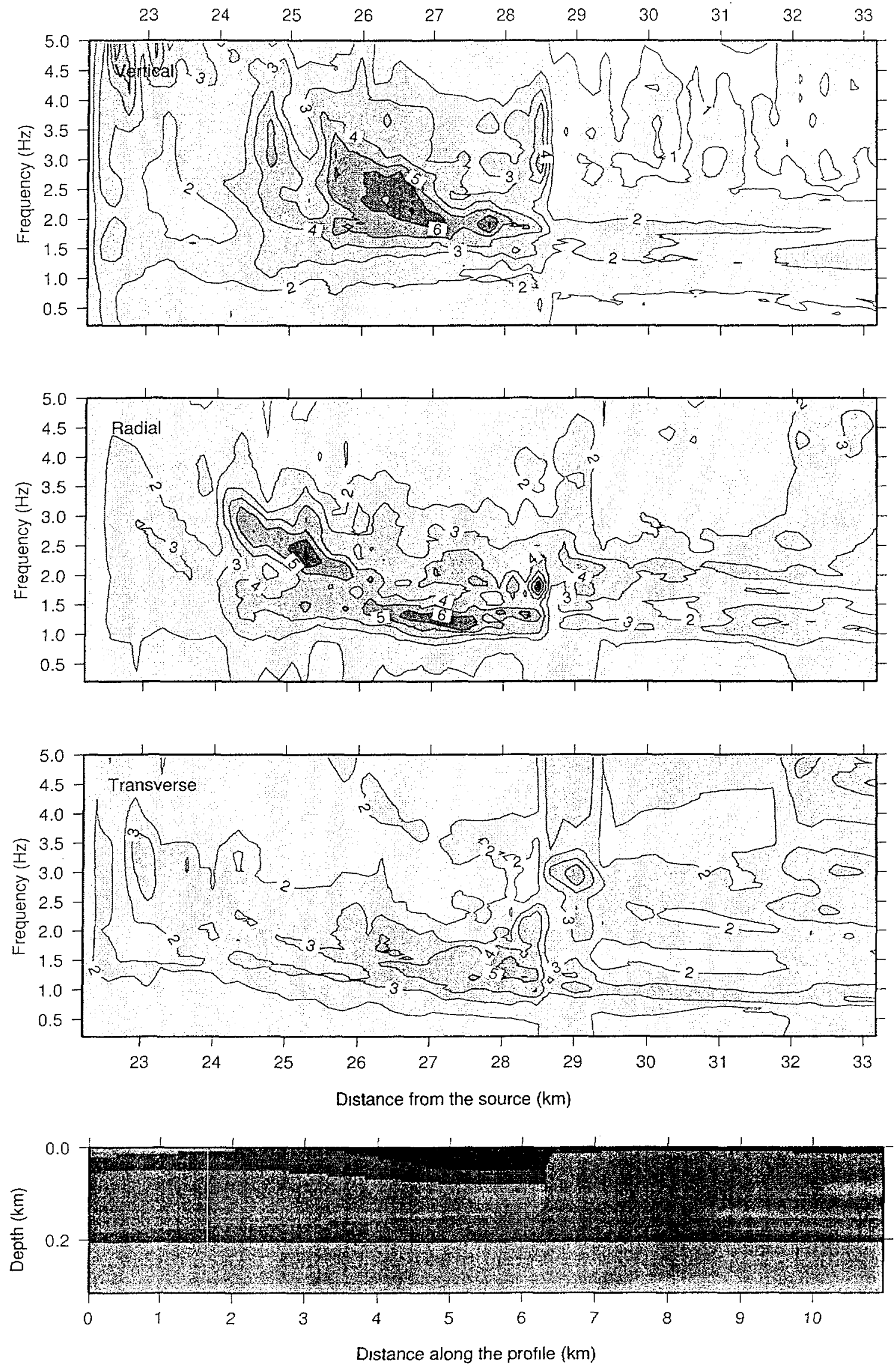

Fig. 6. 

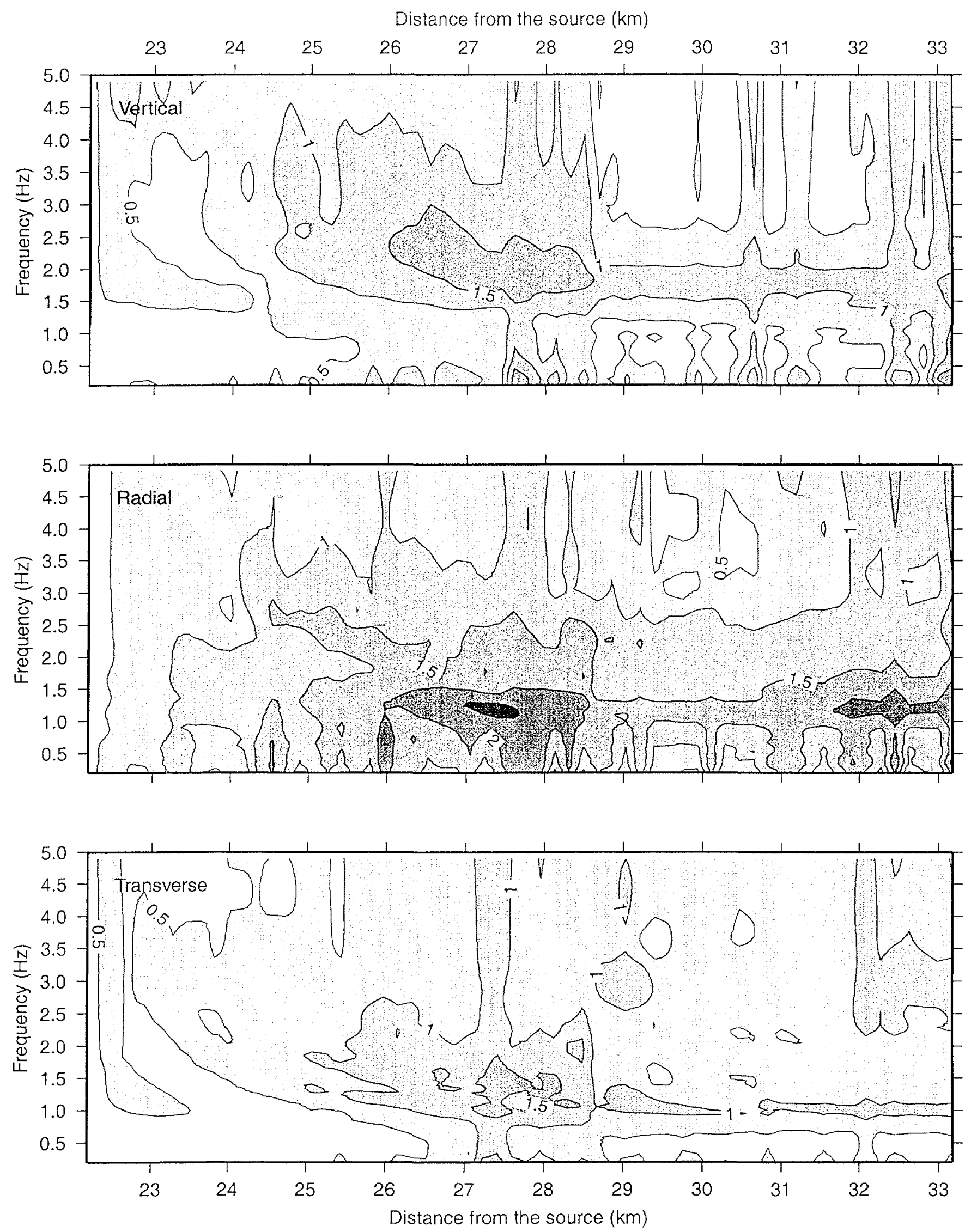

Fig. 7 

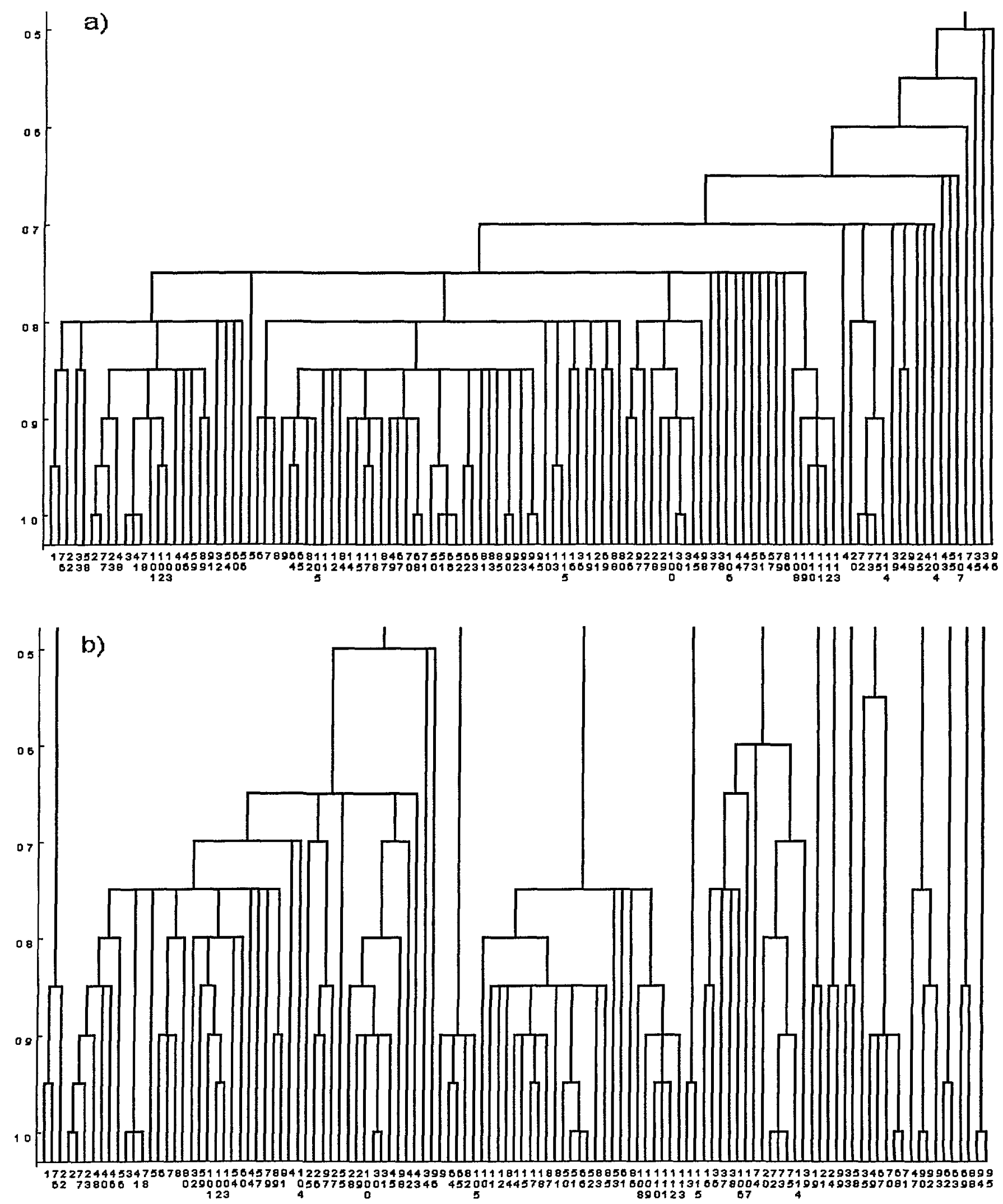

Fig. 8. 


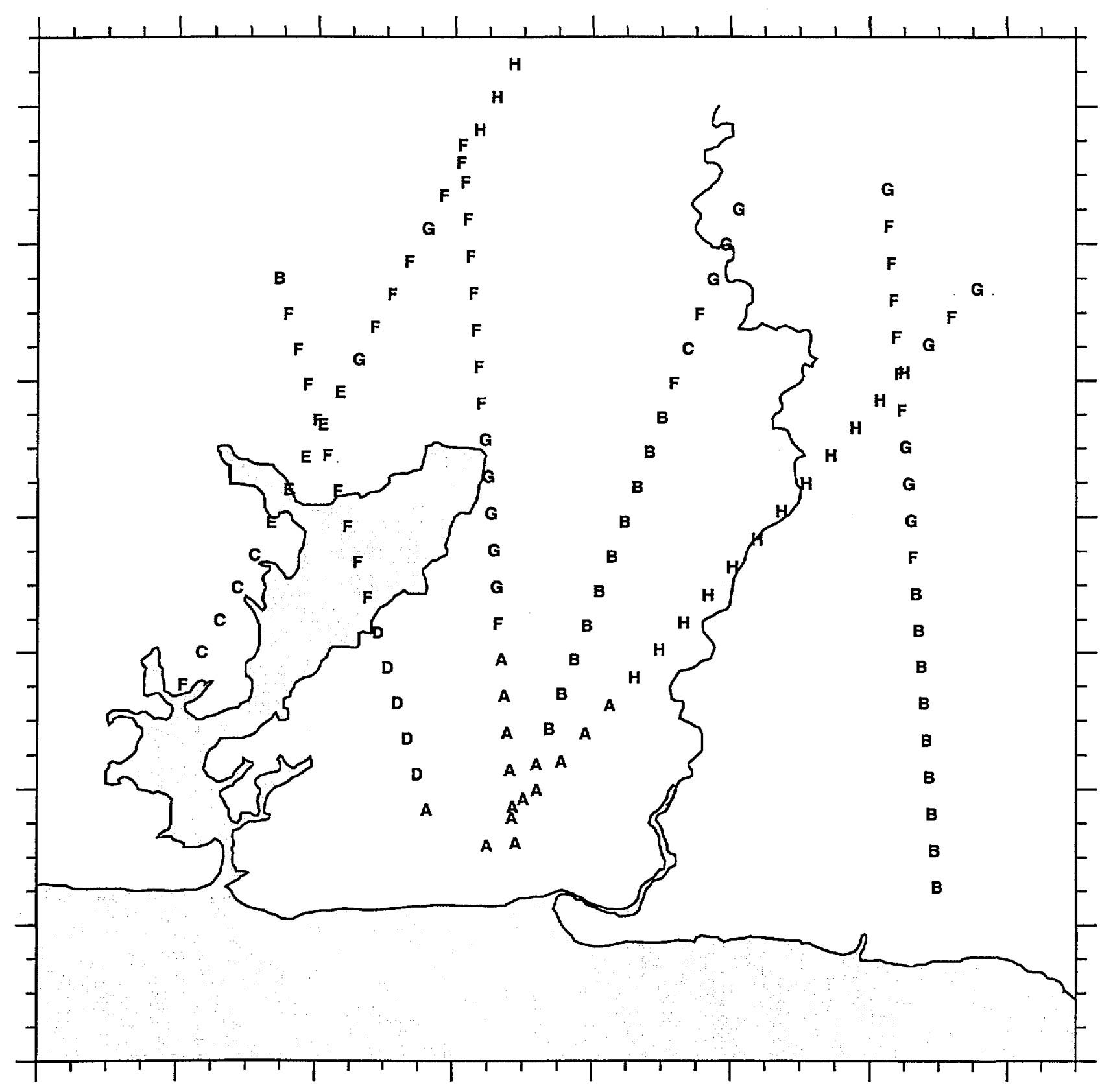

Fig. 9a. 


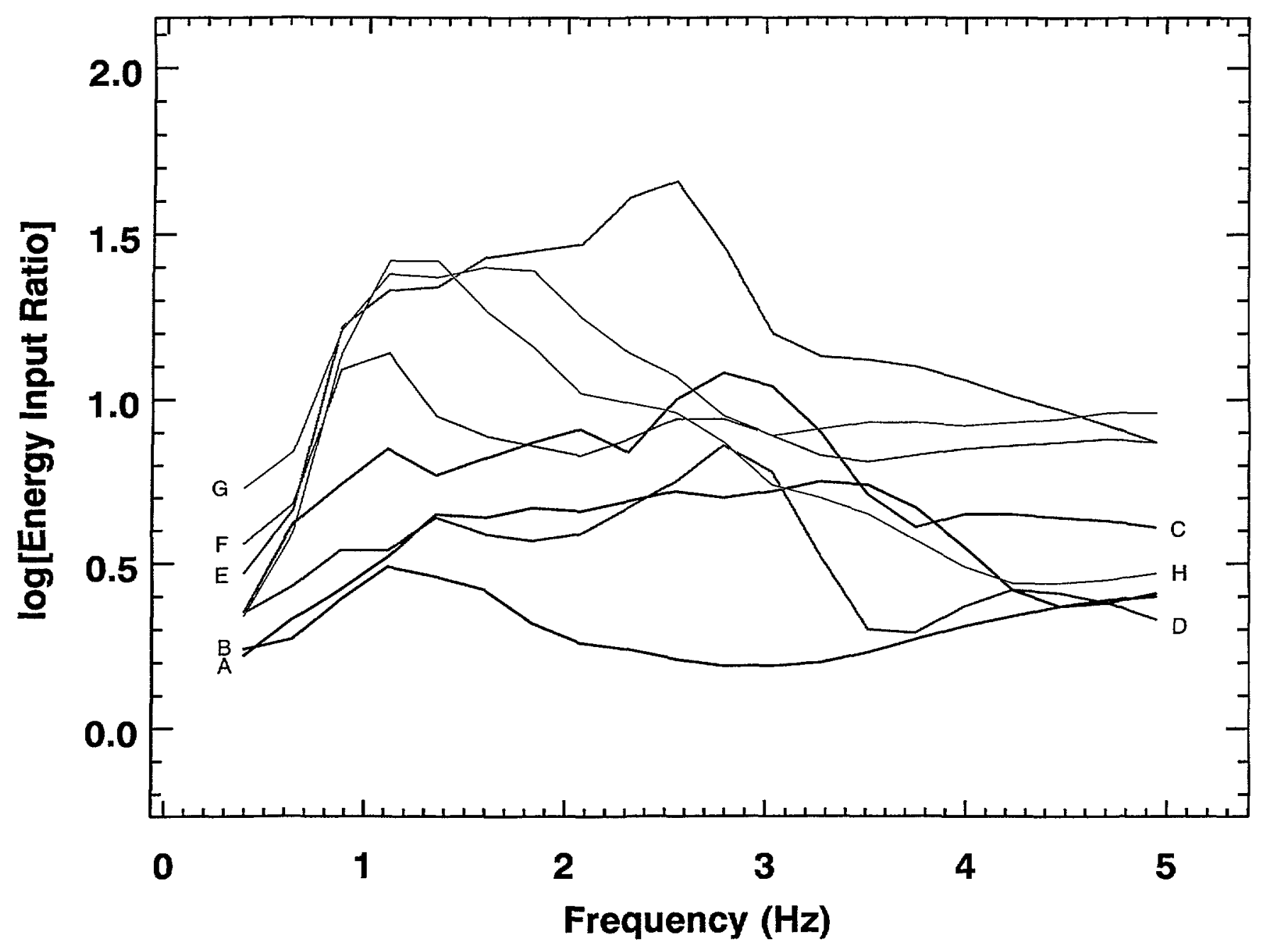

Fig. 9b. 


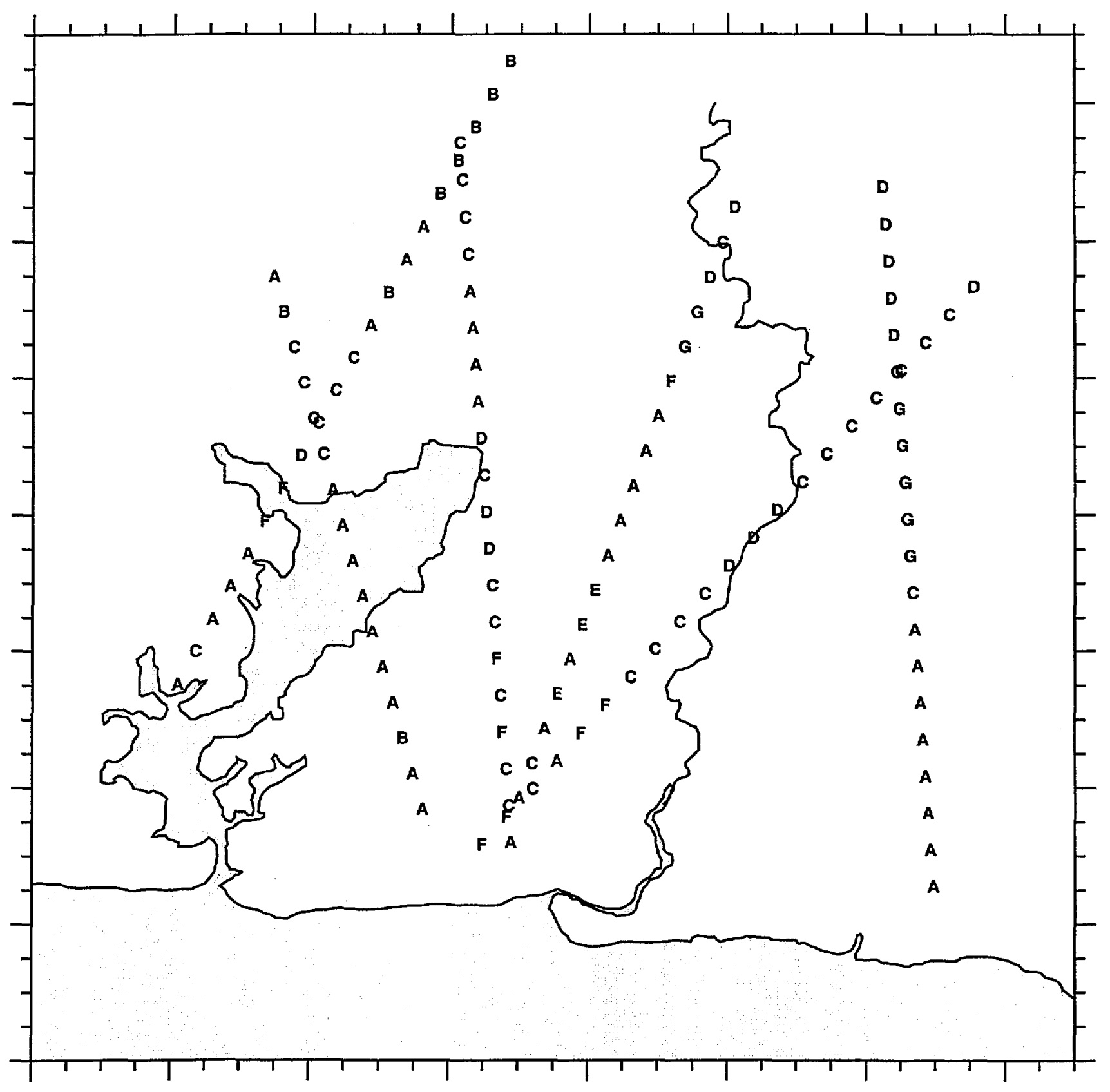

Fig. 10a. 

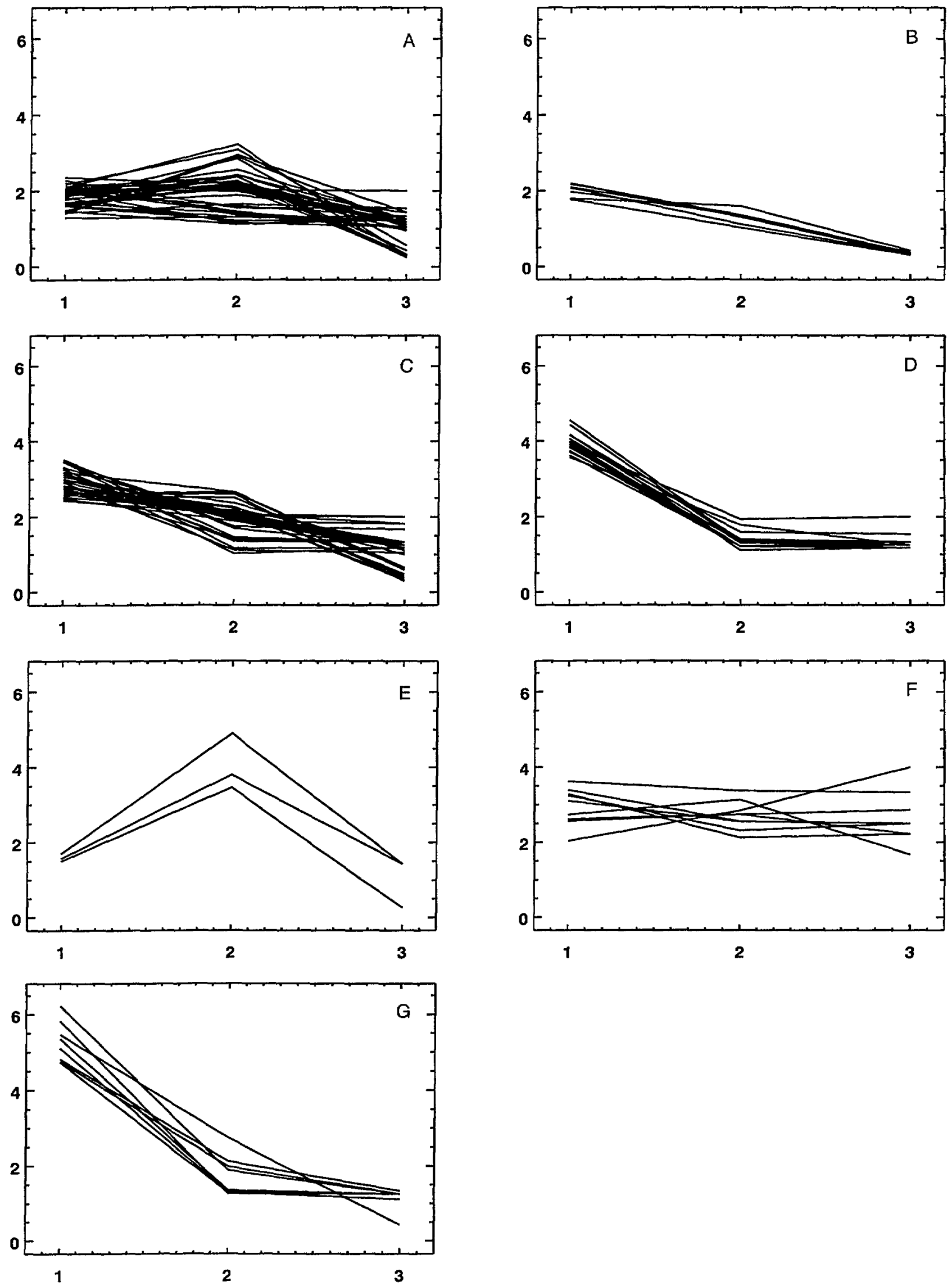

Fig. $10 b$. 


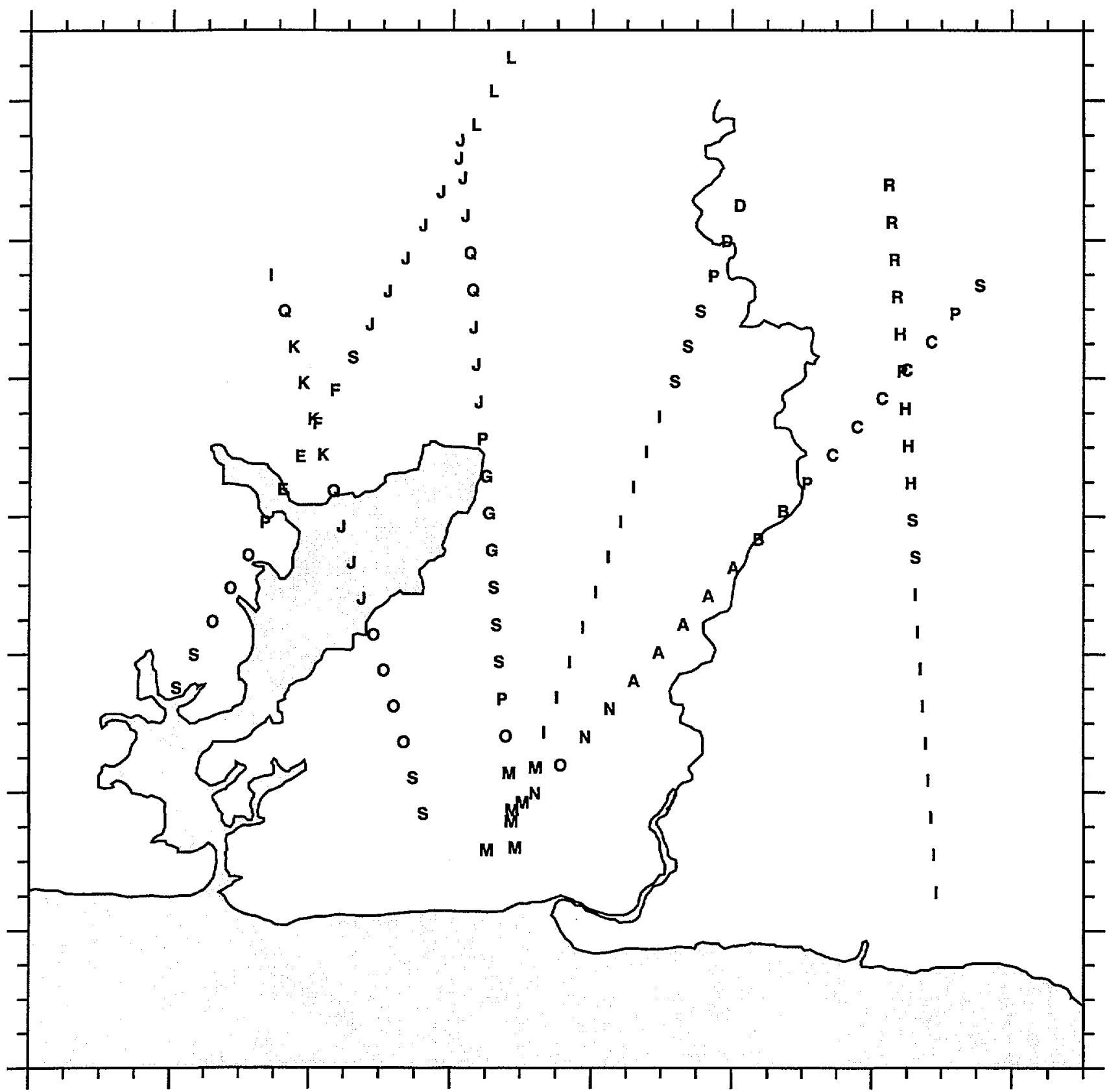

Fig.11.

34 


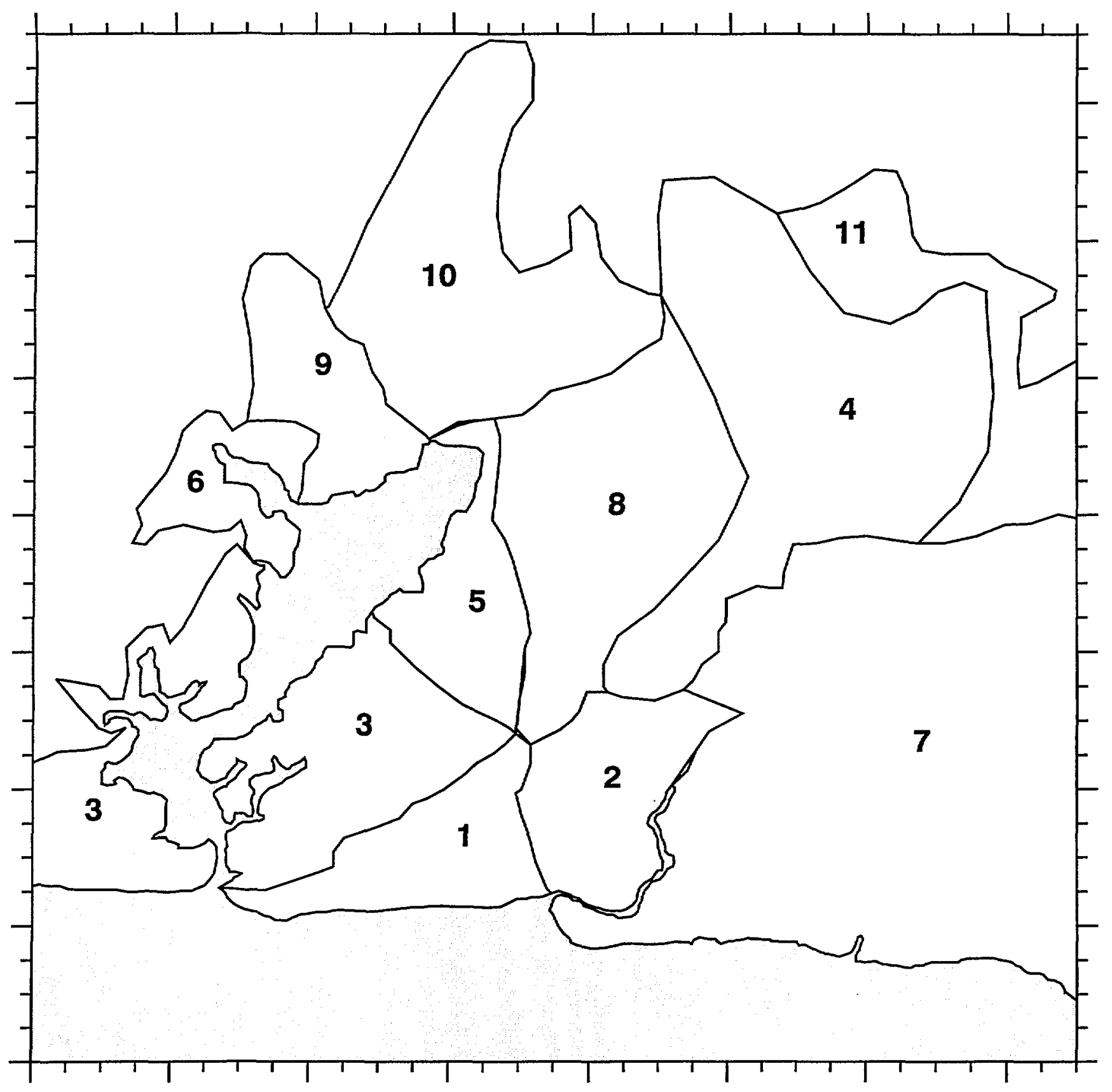

Fig. 12. 

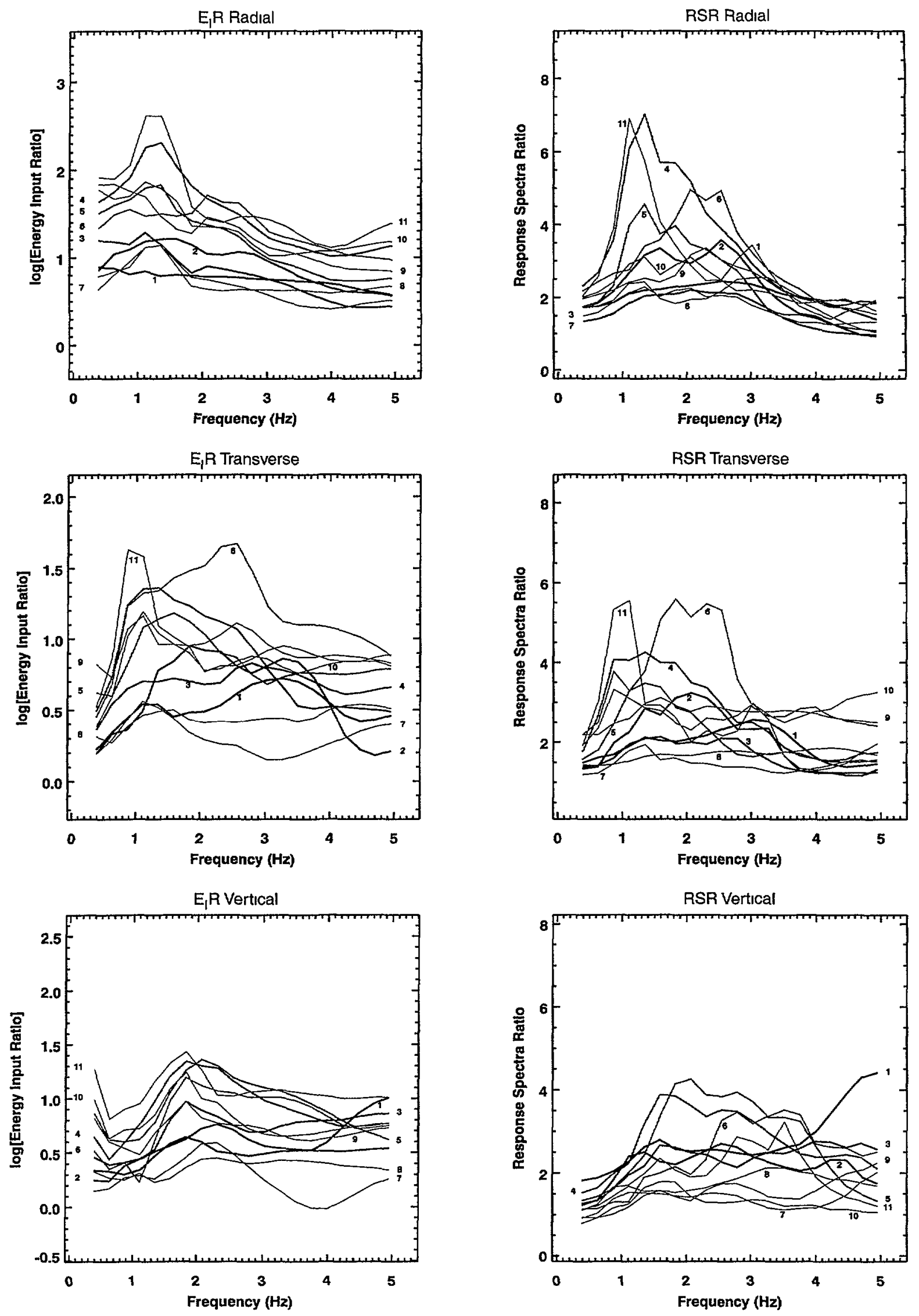

Fig. 13. 